DOE/ER/14710

An Investigation of Homogeneous and Heterogeneous Sonochemistry for Destruction of Hazardous Waste

Final Report - 09/15/1996 - 09/14/2000

\title{
I. Hua
}

September 2000

Work Performed Under Contract No. DE-FG07-96ER14710

For

U.S. Department of Energy

Environmental Management

Washington, DC

By

Purdue University

West Lafayette, IN 
DOE/ER/14710

\section{AN INVESTIGATION OF HOMOGENEOUS AND HETEROGENEOUS SONOCHEMISTRY FOR DESTRUCTION OF HAZARDOUS WASTE \\ FINAL REPORT \\ 09/15/1996 - 09/14/2000}

Dr. Inez Hua

September 2000

Work Performed Under Contract No. DE-FG07-96ER14710

Prepared for the

U.S. Department of Energy Environmental Management

Washington, DC

Prepared by Purdue University

West Lafayette, IN 
Final Report and Accomplishments to Date

An Investigation of Homogeneous and Heterogeneous

Sonochemistry for Destruction of Hazardous Waste

Dr. Inez Hua, Purdue University, School of Civil Engineering

$\underline{\text { Research Objective }}$

The primary objective of this research project is to acquire a deeper fundamental knowledge of acoustic cavitation and cavitation chemistry, and in doing so, to ascertain how ultrasonic irradiation can be more effectively applied to environmental problems. The primary objective will be accomplished by examining numerous aspects of sonochemical systems and acoustic cavitation. During the course of the project, the research group will investigate sonochemical kinetics and reactive intermediates, the behavior of heterogeneous (solid/liquid) systems, and the significance of physical variables during sonolysis. An additional component of the project includes utilizing various techniques to image cavitation bubble cloud development.

$\underline{\text { Research Progress and Implications }}$

This report summarizes results after four years of investigation. Detailed information and results from all years of this investigation can be found in the publications listed at the end of this report, under the heading "Publications Resulting from This Work".

\section{a. Spectroscopic Studies of Organic Free-Radicals Resulting from Sonication of Polychlorinated Biphenyls}

In this section of the progress report, we report the results of our investigation of the sonochemistry of aqueous PCBs. Our studies emphasized identification of reactive intermediates (organic free - radicals) and more stable by-products of PCB destruction. Furthermore, we report the impact of ultrasonic frequency on PCB destruction kinetics and chloride ion recovery. Polychlorinated biphenyls (PCBs) are pollutants of major environmental concern due to their widespread presence, persistence, and implicated human carcinogenicity (Bumpus, Tien et al. 1985; Waid 1986). In 1979, the United States Environmental Protection Agency (U. S. EPA) banned production and distribution of PCBs, and as of 1981, approximately $6.3 \times 10^{8} \mathrm{~kg}$ of PCBs had been produced in the U. S. (Morris and Lester 1994). An estimated $2.3 \times 10^{7} \mathrm{~kg}$ have been destroyed, and the remaining mass is distributed in landfills $\left(1.4 \times 10^{8} \mathrm{~kg}\right)$, has been released into the environment $\left(7.1 \times 10^{7} \mathrm{~kg}\right)$, or is still in use $\left(3.9 \times 10^{8} \mathrm{~kg}\right)$ (May 1992).

At present there are no widely accepted methods for the large-scale remediation of water or soils contaminated with PCBs. Sonication, a new technology, may be used to effectively destroy aqueous PCBs. The application of high power ultrasound to water results in a diverse range of chemical transformations and has been investigated for the destruction of environmental contaminants including p-nitrophenol [Weaver, 1998 \#1524; (Hua, Hochemer et al. 1995), carbon tetrachloride (Hua and Hoffmann 1996), pentachlorophenate (Petrier, Jeunet et al. 1992), and oxygenated fuel additives such as methyl-tert-butyl ether (Kang and Hoffman 1998). Propagation of ultrasonic waves in water generates cavitation bubble clouds (Bhatnagar and Cheung 1994). Bubble implosion and fragmentation produce microregions of extreme conditions. Estimated temperatures within these microregions range from $2000-4000 \mathrm{~K}$ in aqueous solution (Misik, Miyoshi et al. 1995). Thus, reaction pathways similar to those found in 
combustion occur during sonolysis (Henglein 1987) In addition to the direct high temperature decomposition of organic solutes, water also undergoes thermolysis to release radical species $(\bullet \mathrm{H}, \bullet \mathrm{OH}, \mathrm{HOO} \bullet)$ and hydrogen peroxide $\left(\mathrm{H}_{2} \mathrm{O}_{2}\right)$ (Hart, Fischer et al. 1987; Hua and Hoffmann 1997). The concentration of $\bullet \mathrm{OH}$ at the bubble-water interface has been estimated to be $4 \mathrm{mM}$ (Gutierrez and A 1991). These free - radicals attack organic compounds present in solution and comprise another mechanism of sonochemistry.

A detailed description of the experimental methods can be found in publication \#1 at the end of this progress report. We briefly summarize the experimental techniques in this section. Ultrasonic irradiation was performed with two ultrasonic systems. The first system was a high intensity ultrasonic probe system (VCX-400 Sonics and Materials Inc.) which was operated at 20 $\mathrm{kHz}$. The second configuration (USW51 from AlliedSignal Inc.) was a multiple frequency system operating at 205, 358, 618, and $1071 \mathrm{kHz}$. Baseline runs without ultrasonic irradiation showed that in the absence of sonication, PCB losses were insignificant $(<3 \%$ in one hour for both systems).

PCBs were quantified with a Hewlett-Packard 5890 Gas Chromatograph equipped with an electron capture detector (GC/ECD). Chloride ion was determined with a Dionex GP40 ion chromatograph equipped with an ASAI-4 column. Identification of organic products was performed with a Finnigan MAT GVQ gas chromatograph - mass spectrometer (GC-MS) equipped with a DB1 column. Free - radicals were detected with a Bruker ESP300 Electronic Spin Resonance Spectrometer (ESR) operating at $100 \mathrm{kHz}$, at a microwave power of $20 \mathrm{~mW}$ at 9.5 GHz. All reported values are the average of multiple experimental results at each condition set.

Result and Discussion:

We found that the sonolytic destruction of PCBs exhibits pseudo - first order reaction kinetics at a given initial concentration $\left(\mathrm{C}_{0}\right)$ by performing a linear regression between $\ln \left(\mathrm{C} / \mathrm{C}_{0}\right)$ and sonication time, $\mathrm{t}$. $\mathrm{C}=$ concentration of the $\mathrm{PCB}$ congener in each sample, and $\mathrm{C}_{\mathrm{o}}=$ initial PCB concentration. Table 2 reports the rate constants of the three congeners sonicated at 20 $\mathrm{kHz}, 30.8 \mathrm{Wcm}^{-2}$, and with an Ar sparge. 99\% destruction of 2-PCB, 4-PCB, and 2,4,5-PCB occurs within 36, 47, and 29 minutes of sonication, respectively.

Cavitation chemistry encompasses complex pathways involving numerous reactive intermediates, and identification of these intermediates is crucial for elucidating the mechanism of sonochemistry. Free - radicals play an important role in the vapor phase chemistry of the bubble, and also in aqueous reactions.

In order to identify organic free - radicals present at a significant concentration during the sonication of PCBs, we employed ESR with the aid of a spin trap, PBN. PBN reacts with the reactive free - radicals to form more stable spin-adducts, which are then detected by ESR (Kondo and Riesz 1989). The ESR spectrum of a PBN spin adduct exhibits hyperfine coupling of the unpaired election with the ${ }^{14} \mathrm{~N}$ and the $\beta-\mathrm{H}$ nuclei which leads to a triplet of doublets (Rehorek, Henning et al. 1990). The combination of the spin-adduct peak position and peak interval uniquely identifies the structure of a free-radical.

Figure 1 is an ESR spectrum acquired after 10 minutes of sonicating an Ar - saturated solution of 2-PCB and PBN at $20 \mathrm{kHz}$. Samples that were irradiated at different power intensities for the same time period (10 minutes) are compared. Peaks consist of a triplet of doublets with the parameters of $\alpha_{H}=4.2, \alpha_{N}=16.0$, which are characteristic $\alpha$ values for phenyl radical trapped by PBN (Hill and Thornalley 1983). These peaks appeared in all ESR spectra 
obtained from sonicated solutions of 2-PCB $(n=20)$ and 4-PCB $(n=19)$ with irradiation times longer than 10 minutes ( $\mathrm{n}=$ number of experiments).

Note that the integrated peak area (intensity) of the signal correlates with the spin adduct concentration, and is therefore proportional to the initial concentration of free radical in solution (Sargent and Gardy 1976). At the highest power intensity $\left(30.4 \mathrm{Wcm}^{-2}\right)$, the peak intensity is highest. This indicates that the rate of formation of phenyl radical, and therefore, thermolytic cleavage of the biphenyl moiety, is accelerated at higher sound intensities. The enhancement can be understood by considering bubble implosion and the resulting conditions within the bubble. Acoustic intensity is directly related to acoustic pressure as described in Equation 1 (Glickstein 1960), which in turn determines the final temperatures and pressures within the bubble (Equations 2, 3) (Noltingk and Neppiras 1950).

$$
\begin{gathered}
\mathrm{I}=\frac{\mathrm{P}^{2}}{2 \rho \mathrm{C}} \\
\mathrm{T}_{\max }=\mathrm{T}_{\mathrm{o}} \frac{\mathrm{P}_{\mathrm{m}}(\mathrm{k}-1)}{\mathrm{P}_{\mathrm{O}}} \\
\mathrm{P}_{\text {max }}=\mathrm{P}_{\mathrm{o}}\left(\frac{\mathrm{P} \mathrm{m}(\mathrm{k}-1)}{\mathrm{P}_{\mathrm{o}}}\right)\left(\frac{\mathrm{k}-1}{\mathrm{k}-1}\right)
\end{gathered}
$$

where $\mathrm{I}=$ sound intensity, $\mathrm{P}=$ acoustic pressure, $\rho=$ density of water, $\mathrm{C}=$ speed of sound in water. $\mathrm{T}_{\max }, \mathrm{P}_{\max }=$ maximum temperature and pressure at implosion, $\mathrm{T}_{0}=$ ambient temperature of water $\left(22^{\circ} \mathrm{C}\right.$ in our experiments), $\mathrm{P}_{0}=$ pressure in bubble at its maximum size (assumed to be the vapor pressure of water), $\mathrm{P}_{\mathrm{m}}=$ peak pressure of the bubble, which is the sum of the hydrostatic and acoustic pressure ( $\mathrm{P}$, from Eqn. 1), and $\mathrm{k}=$ polytropic index of saturating gas.

Thus, as the sound intensity increases, higher temperatures and pressures exist within the bubble interior, which then enhance the overall decomposition rate of the PCBs. In addition, the formation of organic free - radicals is also enhanced at higher sound intensities. These observations are consistent with previous reports of enhanced decomposition kinetics at higher acoustic intensities (12).

Fig. 2 demonstrates the time variation of the PBN-phenyl spin-adduct accumulation during sonication of 2-PCB. The spin-adduct initially accumulates, corresponding to formation of phenyl radical from the destruction of 2-PCB. Eventually, the intensity of the peak decreases because the concentration of the parent compound, 2-PCB, has decreased, and therefore, the rate of formation of phenyl radical decreases. Also, the spin-adduct itself further reacts during sonolysis. The formation of phenyl radical confirms thermolytic cleavage of the biphenyl rings, which is a key step in PCB destruction. Additional reactions yield other by-products, which were identifiable by GC-MS.

Three groups of products were identified with the mass spectra of sonicated PCB solutions. The first group includes biphenyl and toluene, ethyl benzene, diethylbiphenyl, and dibutenylbiphenyl. The second group includes phenol, propylphenol, di-tert-butylphenol, and cyclohexenyl di-phenol. Biphenyl was found only during the sonication of $54 \mu \mathrm{M} 2-\mathrm{PCB}$, while others were detected as sonication products at lower initial concentration $(5.2 \mu \mathrm{M})$ of 2-PCB. The third group consists of ethyl benzene, diethylbiphenyl, and trichlorophenol detected during the sonication of 2,4,5-PCB.

There are two possible pathways for formation of biphenyl. One is cleavage of $\mathrm{C}-\mathrm{Cl}$ bond followed by $\mathrm{H} \bullet$ addition: 
HUA - Final Report 1996 - 2000

$$
\begin{gathered}
\mathrm{C}_{12} \mathrm{H}_{9} \mathrm{Cl} \rightarrow \mathrm{C}_{12} \mathrm{H}_{9} \bullet+\mathrm{Cl} \bullet \\
\mathrm{C}_{12} \mathrm{H}_{9} \bullet+\mathrm{H} \bullet \rightarrow \mathrm{C}_{12} \mathrm{H}_{10}
\end{gathered}
$$

Another pathway is combination of two phenyl radicals:

$$
\begin{gathered}
\mathrm{C}_{12} \mathrm{H}_{9} \mathrm{Cl} \rightarrow \mathrm{C}_{6} \mathrm{H}_{5} \bullet+\mathrm{C}_{6} \mathrm{H}_{4} \mathrm{Cl} \bullet \\
\mathrm{C}_{6} \mathrm{H}_{5} \bullet+\mathrm{C}_{6} \mathrm{H}_{5} \bullet \rightarrow \mathrm{C}_{12} \mathrm{H}_{10}
\end{gathered}
$$

Bond energies can be used to estimate activation energies (Atkins 1984; Brezonik 1993). Therefore, because the bond energy for $\mathrm{Cl}-\mathrm{C}_{12} \mathrm{H}_{9}$ is lower $\left(397 \mathrm{kJmol}^{-1}\right)$ than that of $\mathrm{C}_{6} \mathrm{H}_{5}-\mathrm{C}_{6} \mathrm{H}_{4} \mathrm{Cl}$ (418 $\mathrm{kJmol}^{-1}$ ), dechlorination is expected to occur more rapidly than recombination of the biphenyl. The ESR data cannot be used to differentiate between these two pathways, however, because $\mathrm{Cl} \bullet$ is difficult to detect directly by ESR, due to its high reactivity (Janzen 1974). The following pathways are proposed for the formation of other compounds in the first group. The thermal degradation of phenyl radical can produce $\mathrm{C}_{6} \mathrm{H}_{4} \bullet$ (Kern, Xie et al. 1992):

$$
\mathrm{C}_{6} \mathrm{H}_{5} \bullet \rightarrow \mathrm{C}_{6} \mathrm{H}_{4} \bullet+\mathrm{H} \bullet
$$

Alkyl fragments result from rupture of the aromatic ring. $\beta$-scission of phenyl radical will yield $n-\mathrm{C}_{4} \mathrm{H}_{3} \bullet$ and acetylene (Sethuraman, Senka et al. 1992):

$$
\mathrm{C}_{6} \mathrm{H}_{5} \bullet \rightarrow \mathrm{HC} \equiv \mathrm{C}-\mathrm{CH}=\mathrm{CH}-\mathrm{CH}=\mathrm{CH} \bullet
$$

$\mathrm{HC} \equiv \mathrm{C}-\mathrm{CH}=\mathrm{CH}-\mathrm{CH}=\mathrm{CH} \bullet \rightarrow \mathrm{HC} \equiv \mathrm{C}-\mathrm{CH}=\mathrm{CH} \bullet+\mathrm{C}_{2} \mathrm{H}_{2}$

The acetylene then reacts with $\mathrm{OH} \bullet$ to form methyl radicals and carbon monoxide:

$$
\mathrm{C}_{2} \mathrm{H}_{2}+\mathrm{OH} \bullet \rightarrow \mathrm{CH}_{3} \bullet+\mathrm{CO}
$$

The formation of group one compounds results from reactions between the phenyl radical and $\mathrm{C}_{6} \mathrm{H}_{5} \bullet, \mathrm{C}_{6} \mathrm{H}_{4} \bullet, \mathrm{C}_{4} \mathrm{H}_{3} \bullet, \mathrm{CH}_{3} \bullet, \mathrm{H} \bullet$ and $\mathrm{C}_{2} \mathrm{H}_{2}$. The presence of methanol as a co-solvent contributes to the formation of $\mathrm{CH}_{3} \bullet$ and $\bullet \mathrm{CH}_{2} \mathrm{OH}$ during sonication of $54 \mu \mathrm{M}$ 2-PCB, but is unlikely to impact the formation of biphenyl. Group two compounds are formed by direct attack of group one compounds by $\bullet \mathrm{OH}$.

The third group of compounds (ethyl benzene, diethylbiphenyl, trichlorophenol) were detected during sonication of 2,4,5-PCB. Cleavage of the biphenyl ring yields a phenyl and a trichlorophenyl radical. Subsequent reaction of the phenyl radical with $\mathrm{C}_{2} \mathrm{H}_{2}$ will result in formation of ethyl benzene, and attack of the trichlorophenyl radical by $\bullet \mathrm{OH}$ will yield trichlorophenol. The presence of hexane as a co-solvent can produce alkane free - radicals and may contribute to the formation of ethyl benzene and diethyl biphenyl. However, during sonication, $\mathrm{C}_{2} \mathrm{H}_{2}$ forms even in the absence of hexane. The wide range of organic by-products detected by GC/MS result from the reaction of aromatic free - radicals with other carbon centered radicals, or with hydroxyl radical $(\bullet \mathrm{OH})$. These experimental results confirm that free radical attack and thermolysis are major mechanisms in sonochemistry.

A major product of PCB sonication is chloride ion; PCBs are rapidly dechlorinated during sonolysis. Dehalogenation during sonication is desirable during the treatment of halogenated compounds for several reasons. Dechlorination to form inorganic chloride is advantageous because of the inert nature of chloride ion compared to other forms of chlorine. Production of inorganic chloride ion is therefore important for successful treatment of chlorinated pollutants. Also, highly substituted compounds tend to be difficult to transform microbially (Bedard and Quensen 1995), and sonication may be a viable pre-treatment.

The chloride recovery ratio was calculated as follows:

$$
\text { Chloride RecoveryRatio }=\frac{\left[\mathrm{Cl}^{-}\right]}{\left([\mathrm{PCB}]_{\mathrm{i}}-[\mathrm{PCB}]_{\mathrm{f}}\right) \times \mathrm{n}}
$$


where $\left[\mathrm{Cl}^{-}\right]=$chloride ion concentration, $\mathrm{mol} \mathrm{L}^{-1}$

$[\mathrm{PCB}]_{\mathrm{i}}=$ initial $\mathrm{PCB}$ concentration concentration, $\mathrm{mol} \mathrm{L}^{-1}$

$[\mathrm{PCB}]_{\mathrm{f}}=$ final $\mathrm{PCB}$ concentration, $\mathrm{mol} \mathrm{L}^{-1}$

$\mathrm{n}=$ number of chlorine atoms per congener

When $>95 \%$ of the parent compound had been destroyed, the chloride recovery ratios were $77 \pm 3 \%, 79 \pm 4 \%$ and $70 \pm 3 \%$ for $2-$, 4-, and 2,4,5-PCB respectively at $20 \mathrm{kHz}$. The ratios were $82 \pm 4 \%$ at $205 \mathrm{kHz}, 74 \pm 1.5 \%$ at $358 \mathrm{kHz}, 84 \pm 1.3 \%$ at $618 \mathrm{kHz}$, and $85 \pm 1 \%$ at $1071 \mathrm{kHz}$ for 2-PCB. Intermediate compounds formed during the decomposition of PCBs probably include volatile chlorinated organic compounds, which may vaporize during gas sparging, and account for the unrecovered chlorine.

The first order plots of PCB destruction in the presence of $0 \mathrm{mM}\left(\mathrm{k}=2.6 \times 10^{-3} \pm 9 \times 10^{-}\right.$

$\left.{ }^{5} \mathrm{~s}^{-1}\right), 0.5 \mathrm{mM}\left(\mathrm{k}=2.4 \times 10^{-3} \pm 5.2 \times 10^{-5} \mathrm{~s}^{-1}\right), 5 \mathrm{mM}\left(1.5 \times 10^{-3} \pm 7.7 \times 10^{-5} \mathrm{~s}^{-1}\right), 50 \mathrm{mM}\left(1.2 \times 10^{-}\right.$

$\left.{ }^{3} \pm 8 \times 10^{-5} \mathrm{~s}^{-1}\right)$ and $200 \mathrm{mM}\left(5 \times 10^{-4} \pm 5 \times 10^{-5} \mathrm{~s}^{-1}\right)$ sodium carbonate are shown in Fig. 4. Compared to sonication without carbonate, the scavenging of $\bullet \mathrm{OH}$ by $200 \mathrm{mM}$ carbonate decreases the rate constant by $\sim 80 \%$. $\bullet \mathrm{OH}$ can react in the gas-phase, the bubble interface, or diffuse into the bulk solution. Carbonate will only scavenge $\bullet \mathrm{OH}$ at the bubble interface or in the bulk phase, and gas-phase reactions of $\bullet \mathrm{OH}$ with PCBs will not be inhibited. Thus, the percentage reduction in the reaction rate indicates only the relative significance of $\bullet \mathrm{OH}$ attack in the liquid phases. The differential role of $\bullet \mathrm{OH}$ attack over a range of ultrasonic frequencies was also investigated with a series of scavenger experiments.

A number of factors determine the observed rate constant in an ultrasonic reactor, and ultrasonic frequency clearly impacts the rate of PCB destruction during sonolysis. However, the mechanism by which ultrasonic frequency enhances reaction rates has not been definitively reported. There are indications that the conditions within the bubble interior vary with frequency, based upon sonoluminescence studies (Didenko and Pugach 1994). Other investigators hypothesize that the flux of hydroxyl radicals is enhanced based on changes in the bubble hydrodynamics during sonolysis (Petrier, Jeunet et al. 1992).

In summary, aqueous PCBs rapidly decompose when exposed to ultrasound. Both thermolysis and free radical attack are important pathways of PCB destruction. Our conclusions are based upon monitoring the concentration of the parent compounds, identifying and measuring the formation of phenyl radical, and characterizing organic by-products during sonolysis. Furthermore, we compare chloride ion recoveries and PCB destruction kinetics over a range of ultrasonic frequencies. Ultrasonic irradiation is optimal at $358 \mathrm{kHz}$, but the chloride recovery is optimal at $1071 \mathrm{kHz}$. The differential role of aqueous $\bullet \mathrm{OH}$ attack was confirmed over a range of ultrasonic frequencies.

\section{b. Decomposition of 1,4 - Dioxane - An Oxygenated Fuel Additive Analogue}

The research reported in this section was directed towards elucidating decomposition products and pathways for 1,4-dioxane during sonolysis at discrete ultrasonic frequencies. The viability of ultrasound and the chemical pathways comprising sonochemical destruction of dioxane are explored. The results from this particular compound can then be extrapolated to other ethers and cyclic ethers which persist in and contaminate the environment. Ultrasonic frequency is also examined as a component of optimal ultrasonic reactor design and operation.

Because 1,4-dioxane persists in the natural environment and can migrate rapidly through aquifers, its presence in both surface and groundwater is problematic (Lesage, Jackson et al. 1990; Abe 1999; Jackson and Dwarakanath 1999). A current treatment technology for removing 
1,4-dioxane from contaminated waste streams is by distillation, but this process is rather expensive [, \#532]. Other treatment methods, including activated carbon (Johns, Marshall et al. 1998) and air stripping [, \#532], provide inefficient removals due to the high aqueous solubility $\left(4.31 \times 10^{5} \mathrm{mg} / \mathrm{L}\right)$ and low vapor pressure $\left(37 \mathrm{~mm} \mathrm{Hg} @ 25^{\circ} \mathrm{C}\right)$ which are characteristic of 1,4dioxane (Lagrega, Buckingham et al. 1994). Moreover, the aforementioned treatment methods do not destroy the target compound but rather transfer it from one phase to another. Sonolysis is a potential destructive technique which has been effectively applied to other ethers (Kang and Hoffman 1998; Kang, Hung et al. 1999).

Experimental Materials and Methods

A more detailed description of the experimental procedures may be found in publication \#6 at the end of this progress report. All sonolytic experiments were performed with an AlliedSignal URS Ultrasonic Transducer powered by an Allied Signal R/F generator (256 W maximum output). Four ultrasonic frequencies were employed during the experiments (205, 358, 618, and $1071 \mathrm{kHz}$ ). 1,4-dioxane was quantified by a Hewlett-Packard (HP) 5890 Gas Chromatograph equipped with a flame ionization detector (FID) and an HP 7673 autosampler. EGD was identified using the solid-phase extraction (SPME) method from Supelco combined with GC/MS (Stefan and Bolton 1998). All organic acids were detected and quantified using a Dionex Ion Chromatograph (IC) equipped with a CD 20 Conductivity Detector (Stefan and Bolton 1998). Formaldehyde and glyoxal were derivatized with 2,4-dinitrophenylhydrazine (DNPH) and then measured by high performance liquid chromatography (HPLC) (Fung and Grosjean 1981).

The total organic carbon (TOC) was determined with a Shimadzu model TOC-5000A analyzer according to Standard Methods (APHA 1995). All experiments (analysis by GC/FID, HPLC, TOC) except the organic acid studies (IC detection) were performed in duplicate with two injections made for each sample. The organic acid investigations were performed in triplicate with two injections made for each sample.

Results and Discussion

Pseudo first order plots of 1,4-dioxane degradation with varying ratios of sparge gas at a frequency of $358 \mathrm{kHz}$ are shown in Figure 4. 1,4-Dioxane degrades more quickly in the presence of pure oxygen than with pure Ar, an inert gas. Nevertheless, it is clear that a combination of the sparge gases $\mathrm{O}_{2}$ and Ar lead to higher degradation rates than either gas individually; the highest degradation rate occurs at a $75 \% \mathrm{Ar} / 25 \% \mathrm{O}_{2}$ ratio. This approximate ratio has also been demonstrated to be optimal by other investigators (Hart and Henglein 1985).

In order to elucidate the reaction mechanisms of 1,4-dioxane degradation during sonolysis, the intermediates of 1,4-dioxane were determined and quantified using a variety of analytical methods as discussed previously. The by-product formation at $358 \mathrm{kHz}$ is shown in Figure 5. After 120 minutes, $96 \%$ of the initial 1,4-dioxane concentration was depleted, and five major reaction intermediates were detected: ethylene glycol diformate (EGD) $\left(\mathrm{C}_{4} \mathrm{H}_{6} \mathrm{O}_{4}\right)$, methoxyacetic acid $\left(\mathrm{C}_{3} \mathrm{H}_{6} \mathrm{O}_{3}\right)$, formic acid $\left(\mathrm{CH}_{2} \mathrm{O}_{2}\right)$, glycolic acid $\left(\mathrm{C}_{2} \mathrm{H}_{4} \mathrm{O}_{3}\right)$, and formaldehyde $\left(\mathrm{CH}_{2} \mathrm{O}\right)$. Formate is produced at the fastest rate followed by EGD. Methoxyacetic acid and formaldehyde are formed at similar rates followed by glycolic acid which appears after an induction period of 30 minutes. In the following discussion, we postulate the major pathways leading from 1,4-dioxane to its subsequent mineralization based on the by-products observed during the ultrasonic reaction conditions. We propose a mechanism of sonolytic 1,4-dioxane destruction that occurs predominantly with reactions involving $\bullet \mathrm{OH}$ in the gas phase and at the interfacial region of the cavitation bubble. 
The reaction between 1,4-dioxane (I) and $\bullet \mathrm{OH}$ initially begins with an $\mathrm{H}$-abstraction at any of the carbons (due to symmetry) leading to the 1,4-dioxanyl radical (II) and water as shown in Figure 6 (Eibenberger, Schulte-Frohlinde et al. 1980; Platz, Sehested et al. 1997; Maurer, Hass et al. 1999). Further reactions of the 1,4-dioxanyl radicals with $\mathrm{O}_{2}$ at diffusion controlled rates lead to the peroxyl radicals (III) which normally undergo head-to-head termination reactions (bimolecular rate constants $>10^{9} \mathrm{M}^{-1} \mathrm{~s}^{-1}$ ) to form the tetroxide intermediate (IV) (Schuchmann and Von Sonntag 1982). Once formed, this tetroxide intermediate rapidly decomposes to form $\alpha$-oxyl radicals (V) and molecular oxygen (Schuchmann and Von Sonntag 1982; Stefan and Bolton 1998). These $\alpha$-oxyl radicals will undergo two primary types of reactions: 1) $\beta$-C-C fragmentation leading to the formation of radical VI or 2) a 1,2-H-shift leading to $\alpha$-hydroxyl radicals (X) (Nese, Schuchmann et al. 1995). Further reactions involving radicals VI consume oxygen and form peroxyl radicals (VII) which can then dimerize to yield a tetroxide intermediate (VIII). The tetroxide rapidly decomposes to ethylene glycol diformate (EGD) (IX) and hydrogen peroxide (Fig. 6).

The further decomposition of EGD is initiated with $\mathrm{H}$-abstraction by $\bullet \mathrm{OH}$ attack (Fig. 7). Transformation proceeds in the presence of $\mathrm{O}_{2}$ by forming another tetroxide intermediate which decomposes via either a free radical mechanism or a concerted mechanism (Schuchmann and Von Sonntag 1982). The free radical pathway forms two alkoxyl radicals (XII) and $\mathrm{O}_{2}$. The alkoxyl radicals (XII) then undergo $\beta$-scission and react to form aldehyde esters (XIV) and formic acid (XV). The aldehyde esters are unstable and quickly hydrolyze to formic acid (XV) and glycolaldehyde (XVI) (Stefan and Bolton 1998). Additional reactions involving glycolaldehyde (XVI) and hydroxyl radicals will lead to the rapid formation of glyoxal (XVII) and glycolic acid (XVIII). The concerted mechanism involves the formation of $\mathrm{H}_{2} \mathrm{O}_{2}$ and an ester intermediate (XIII) which can then hydrolyze to glycolic (XVIII) and formic acid (XV) (Stefan and Bolton 1998).

Although there are previous investigations of 1,4-dioxane decomposition due to oxidation, photolysis, or other destruction methods, only one study reports methoxyacetic acid as an intermediate (Stefan and Bolton 1998). The researchers examined the degradation of 1,4dioxane in dilute aqueous solution by irradiation with $\mathrm{UV} / \mathrm{H}_{2} \mathrm{O}_{2}$ and proposed that methoxyacetic acid was eventually formed from an $\alpha$-oxyl radical in a process involving $\mathrm{HO}_{2} \bullet$ as a reducing agent under reducing conditions.

It is unlikely that reducing conditions exist in the sonochemical reactor under our conditions. It is therefore hypothesized that the formation of methoxyacetic acid occurs via the 1,2-H-shift pathway mentioned previously (Fig. 6). Since oxygen is more electronegative than carbon, it is inclined to attract the unpaired electron residing on the carbon (denoted $\mathrm{C}_{1}$ in Fig. 8) (Carey 1996). The bond cleavage, promoted by the extreme conditions inside the cavitation bubble then occurs between the weakened $\mathrm{C}_{4}-\mathrm{O}$ bond (Fig. 8) leading to the formation of a double bond between the oxygen and $\mathrm{C}_{1}$. This ring opening leads to the creation of the carboxyl radical XIX which will react with $\mathrm{O}_{2}$ and, in a series of steps involving a tetroxide, results in the formation of radical XXI and $\mathrm{O}_{2}$. The radical then undergoes $\alpha$-cleavage to release formaldehyde (XXII) and subsequently form methoxyacetic acid (XXIV).

It is hypothesized that methoxyacetic acid will then continue to react with the hydroxyl radicals through $\mathrm{H}$-abstraction at the methyl carbon followed by $\beta$-scission. The resulting intermediates created are formaldehyde (XXII) and the formyl methyl radical (XXV). Formaldehyde is rapidly oxidized to formic acid which eventually oxidizes to $\mathrm{CO}_{2}$ (Carey 1996). The formyl methyl radical can combine with $\bullet \mathrm{OH}$ to form glycolic acid. Trace amounts of 
oxalate were measured during the sonication of 1,4-dioxane but only appeared subsequent to the formation of glycolic acid. The pathway for glycolic acid oxidation to $\mathrm{CO}_{2}$ has previously been shown to produce formate and oxalate as intermediates prior to mineralization (Stefan and Bolton 1998). In this study, when aqueous glycolic acid was sonicated, formate and oxalate were detected in significant amounts, thereby corroborating the proposed pathway in Figure 5. Also, in the proposed reaction schemes, the generation of formic acid occurs in a number of pathways which is consistent with its presence at the highest concentration among the intermediates (Fig. 2).

Although there are other possible alternative pathways for 1,4-dioxane decomposition leading to different by-products, they are probably minor. A total carbon balance on 1,4-dioxane and its by-products was determined as follows:

$$
\left[\text { Total carbon }(\mathrm{mM} \text { as C) }]_{t}=[1,4 \text {-dioxane }]_{t}+\sum[\text { intermediates }]_{t}+[\text { Carbon mineralized }]_{t}(13\right.
$$

The total carbon mineralized (converted to $\mathrm{CO}_{2}$ ) was determined using a TOC analyzer. Regardless of the frequency, approximately $80-85 \%$ of the initial carbon is accounted for as the parent compound, as an intermediate, or as $\mathrm{CO}_{2}$. Possible physical loss mechanisms include vaporization; continuous sparging is necessary to maintain gas saturation during the experiments. Sparging studies in the absence of ultrasound were performed on $1.0 \mathrm{mM}$ solutions of each intermediate for two hours in order to ascertain volatilization losses. During that time period, there was a maximum loss of 3-5\% of each compound. By assuming a 5\% loss for each compound over time, nearly $90 \%$ of the organic carbon can be accounted for.

The impact of frequency on sonolytic environmental processes has been shown to be significant (Cum, Galli et al. 1992; Petrier, Jeunet et al. 1992; Entezari and Kruus 1994; Entezari and Kruus 1994; Entezari, Kruus et al. 1997; Hung and Hoffmann 1999; Kang, Hung et al. 1999). The effect of sonolysis on the degradation rate of 1,4-dioxane was studied over a range of frequencies using the same transducer and reactor system for each experiment to keep the power/area and power/volume ratios consistent. The fastest degradation occurs at a frequency of $358 \mathrm{kHz}$ followed by 618, 1071, and $205 \mathrm{kHz}$, as shown in Fig. 10

Since there have been no other in depth investigations comparing intermediate formation of sonicated species at several frequencies, the by-products of 1,4-dioxane decomposition were examined at all frequencies $(205,358,618$, and $1071 \mathrm{kHz})$ in this study. The results from the formation of EGD, methoxyacetic acid, formic acid, and formaldehyde are shown in Figures 11 12. Comprehensive TOC studies at 208,618 , and $1071 \mathrm{kHz}$ accounted for approximately 80$85 \%$ of all carbon, commensurate with what was observed at $358 \mathrm{kHz}$. As seen in Figure 7, the degradation rate of 1,4-dioxane is most rapid at 358 followed by 618, 1071, and $205 \mathrm{kHz}$. The accumulation of each intermediate is clearly the greatest at $358 \mathrm{kHz}$, consistent with the parent compound being decomposed most rapidly at this frequency. The accumulation of most intermediates follows the ordering of the 1,4-dioxane degradation rates. However, production of EGD, formaldehyde, and formic acid is slowest at $205 \mathrm{kHz}$.

The order of methoxyacetic acid accumulation is different, however (358, 618, 205, followed by $1071 \mathrm{kHz}$ ). Methoxyacetic acid accumulates more rapidly at 205 than at $1071 \mathrm{kHz}$ during most of the experiment. The most violent conditions and the hottest temperatures and pressures within the cavitation bubble tend to decrease as the frequency is increased. Evidence for this has been corroborated by both studies on sonoluminescence (Walton and Reynolds 1984), and acoustic cavitation field predictions (Laborde, Bouyer et al. 1998). By examining the 
reaction scheme leading to the formation of methoxyacetic acid (Fig.3), it is possible that these extreme conditions are able to cleave radical X more extensively after the 1,2-H-shift takes place at $205 \mathrm{kHz}$ than during cavity collapse at $1071 \mathrm{kHz}$. Although extreme conditions in cavitation bubbles decrease with increasing frequency, cavitation intensity at 358 and $618 \mathrm{kHz}$ is still substantial along with an increased number of these radicals capable of reaching the gas phase via higher induced mass transfer rates. At $1071 \mathrm{kHz}$, the mass transfer of solutes into and out of the cavitation bubble is greater than at lower frequencies, but the energy available for bond cleavage upon bubble implosion is diminished. This distinction accounts for overall higher concentrations of methoxyacetic acid produced at 358 and 618 than at 205 and $1071 \mathrm{kHz}$. Nevertheless, the overall conclusion from these by-product results indicates that the decomposition pathways at each frequency are analogous and that $\bullet \mathrm{OH}$ oxidation is the major mechanism over the whole range of frequencies.

By using ultrasound, a refractory contaminant such as 1,4-dioxane can be decomposed into smaller short chain organics which are then capable of being degraded more effectively by other means such as biological processes. The results of this investigation have shown that 1,4dioxane is sonolytically decomposed primarily via free radical pathways leading to the formation of major intermediates ethylene glycol diformate and methoxyacetic acid followed subsequently by formaldehyde, formic, and glycolic acids. These free radical pathways dominate over the entire range of frequencies investigated $(205,358,618$, and $1071 \mathrm{kHz})$. Sparging gases and frequency also play an important role in optimizing sonochemical effects.

\section{c. Sonochemical Decomposition of Dichlorvos}

Dichlorvos is a chlorinated organophosphate insecticide which is released into the environment through its manufacture and use (Howard 1991). Worldwide production in 1989 was estimated as 4 million $\mathrm{kg} / \mathrm{yr}$ (International Programme on Chemical Safety 1989), and in 1994, over $2250 \mathrm{~kg}$ of dichlorvos were applied in the state of California (University of California Statewide Integrated Pest Management Project 1997). In all environments, hydrolysis is the main pathway for degradation of dichlorvos. In environmental waters, the half-life of dichlorvos is between 20 and 80 hours at $\mathrm{pH}$ values between 4 and 9; faster degradation occurs at higher $\mathrm{pH}$ values (Howard 1991). Biodegradation has also proven to be important (Lamoreaux and Newland 1978; Lieberman and Alexander 1983). Treatment methods such as biodegradation (Lamoreaux and Newland 1978; Lieberman and Alexander 1983), ozonolysis (Koga, Kadakami et al. 1992), Fenton's reagent ( $\mathrm{Lu}$, Chen et al. 1997; Lu, Chen et al. 1999), and photocatalysis (Harada, Hisanaga et al. 1990; Lu, Roam et al. 1993; Lu, Roam et al. 1994; Lu, Roam et al. 1995; Mengyue, Shifu et al. 1995) have been applied to the decomposition of dichlorvos. This study introduces sonolysis as a possible complement to the aforementioned treatment methods.

Previous studies of the decomposition of dichlorvos by advanced oxidation technologies have identified the mineralization products chloride and phosphate but have not identified reaction intermediates (Harada, Hisanaga et al. 1990; Lu, Roam et al. 1993; Lu, Roam et al. 1995; Mengyue, Shifu et al. 1995; Lu, Chen et al. 1997). A primary objective of this study was to identify and quantify key intermediates in the transformation of dichlorvos. Other objectives were to ascertain the impact of acoustic output power and sparge gas on the sonolytic decomposition kinetics, to demonstrate the partial mineralization of dichlorvos, and to propose a reaction pathway for dichlorvos decomposition. 


\section{Materials and Methods}

The experimental methods for this section of the progress report are described in detail in publication \#4 at the end of this progress report. Each experiment was performed with a UES1.5-660 Pulsar (Ultrasonic Energy Systems, Panama City, FL) generator and ultrasound transducer vessel.

For every one minute of operation time, the solution was irradiated for 48.9 seconds. Thus, the effective sonication time appears in all figures and calculations. Three replicate experiments were performed for each reactor variable (e.g., sparge gases and power). Three replicate experiments were also executed for the study of reaction intermediates as well as total organic carbon (TOC). All samples were analyzed at least in duplicate.

The analysis of dichlorvos was performed with a Hewlett-Packard Model 5890 Series II Gas Chromatograph / Electron Capture Detector (GC/ECD) The TOC was analyzed with a Shimadzu model TOC-5000A Total Organic Carbon Analyzer. Ions were analyzed with an ion chromatograph (IC) from Dionex (Dionex IonPac ${ }^{\circledR}$ AS4A anion column with an IonPac ${ }^{\circledR}$ AG4A guard column).

$\underline{\text { Results }}$

The kinetics of dichlorvos decomposition were best described by a first order decay. Table 3 lists the first order rate constants (mean \pm standard deviation) obtained from the kinetic experiments. The rate at which dichlorvos was destroyed during sonication at $500 \mathrm{kHz}$ increased when the total acoustic power output was increased from $86 \mathrm{~W}\left(\mathrm{k}=0.0184 \pm 0.0014 \mathrm{~min}^{-1}\right)$ to 161 $\mathrm{W}\left(\mathrm{k}=0.0374 \pm 0.0023 \mathrm{~min}^{-1}\right)$. There is also a significant enhancement of the first order decomposition rate constant when a mixture of $\mathrm{Ar}$ and $\mathrm{O}_{2}$ gas is used to saturate the solution $(\mathrm{k}=$ $\left.0.0792 \pm 0.0051 \mathrm{~min}^{-1}\right)$. This is consistent with previous investigators' results [Hua, 1995 \#102; Drijvers, 1998 \#193].

Figures 12 and 13 presents the accumulation of formate and dimethyl phosphate, respectively. Dimethyl phosphate is of particular interest, because its rate of accumulation reflects the rate of the initial transformation step(s). With $\mathrm{O}_{2}$ and $\mathrm{Ar} / \mathrm{O}_{2}$ sparge gases, the dimethyl phosphate ion concentration reached a plateau of approximately $3.6 \times 10^{-4} \mathrm{M}$ before declining. The concentration of formate ion increased quite rapidly in the case of $\mathrm{O}_{2}$ and $\mathrm{Ar} / \mathrm{O}_{2}$ sparges to approximately $3.1 \times 10^{-4} \mathrm{M}$, while the Ar sparge did not exhibit the rapid accumulation of formate ion.

The mineralization products phosphate and chloride were also quantified, as shown in Figure 14 and 15. The $\mathrm{O}_{2}$ and $\mathrm{Ar} / \mathrm{O}_{2}$ sparge gases rapidly approached the maximum theoretical concentration of $1.0 \times 10^{-3} \mathrm{M}$ for chloride ion. However, the concentration of chloride did not reach the theoretical maximum with the Ar sparge. Phosphate ion accumulated slowly, regardless of the sparge gas.

The TOC of the reaction solution was monitored during sonication to determine the impact of dissolved gas on dichlorvos mineralization. Figure 4 shows the decrease in the TOC concentration with sonication time. The decrease in the TOC concentration can be assumed to be equal to the concentration of $\mathrm{CO}_{2}$ produced. The production of $\mathrm{CO}_{2}$ ranges from $4.0 \times 10^{-4}$ to $6.5 \times 10^{-4} \mathrm{M}$ after 48.9 minutes of sonication, depending on the sparge gas. The conversion of the initial TOC to $\mathrm{CO}_{2}$ at $161 \mathrm{~W}$ and 48.9 minutes of sonication was $19.5 \%$ for $\mathrm{Ar}, 21.5 \%$ for $\mathrm{O}_{2}$, and $31 \%$ for the $\mathrm{Ar} / \mathrm{O}_{2}$ sparge gas.

Discussion

Based upon our experimental results, and the results of other investigations, a pathway is proposed for dichlorvos mineralization (Figure 5) during sonication. The complete 
mineralization would result in production of carbon dioxide, phosphate, chloride, and water by the following reaction:

$$
\mathrm{C}_{4} \mathrm{H}_{7} \mathrm{Cl}_{2} \mathrm{O}_{4} \mathrm{P}+9 / 2 \mathrm{O}_{2}--->4 \mathrm{CO}_{2}+\mathrm{H}_{2} \mathrm{O}+2 \mathrm{Cl}^{-}+\mathrm{PO}_{4}^{3-}+5 \mathrm{H}^{+}
$$

Products of dichlorvos sonolysis are defined as any compound appearing on the right side of equation 1. Any other compounds identified during decomposition of dichlorvos are considered reaction intermediates. The reaction intermediates and products that are boxed in Figure 5 were identified and quantified in this study by total organic carbon analysis for $\mathrm{CO}_{2}$ and ion chromatography for dimethyl phosphate, phosphate, formate, and chloride. The bond most susceptible to hydrolysis is the vinyl phosphate bond (Pearson and Songstad 1967; Mabey and Mill 1978). Hydrolysis results in dimethyl phosphate $\left(\mathrm{C}_{2} \mathrm{H}_{4} \mathrm{PO}_{4}^{-}\right)$and dichlorovinyl alcohol $\left(\mathrm{C}_{2} \mathrm{H}_{2} \mathrm{Cl}_{2} \mathrm{O}\right.$ ) (Hodgson and Casida 1962; Patil and Shingare 1994; Khandelwal and Wedzicha 1998). This is of particular interest because hydrolysis reactions are accelerated during sonolysis (Hua, Hochemer et al. 1995; Tuulmets and Raik 1999).

Dimethyl phosphate can further react to form monomethyl phosphate $\left(\mathrm{CH}_{4} \mathrm{PO}_{4}{ }^{-}\right)$and methanol $\left(\mathrm{CH}_{3} \mathrm{OH}\right)$ (Bunton, Mhala et al. 1960; Rapp, Nogueira et al. 1997). Monomethyl phosphate can hydrolyze to phosphate $\left(\mathrm{PO}_{4}^{3-}\right)$ and methanol (Bunton, Llewellyn et al. 1958; Rapp, Nogueira et al. 1997; Florian and Warshel 1998). The methanol formed from hydrolysis of dimethyl phosphate and monomethyl phosphate can react with hydroxyl radical to create formic acid $\left(\mathrm{CH}_{2} \mathrm{O}_{2}\right)$, which then ionizes to formate $\left(\mathrm{CHO}_{2}{ }^{-}\right)$(Downes and Sutton 1973; Toy and Stringham 1993; O'Shea, Aguila et al. 1998). Both dimethyl phosphate and phosphate are identified and quantified in this study. The dimethyl phosphate accumulates to $\sim 3.8 \times 10^{-4} \mathrm{M}$ with the $\mathrm{O}_{2}$ and $\mathrm{Ar} / \mathrm{O}_{2}$ sparges before reaching a plateau and decreasing. At the plateau, the rate of dimethyl phosphate accumulation is equal to its degradation rate. The dimethyl phosphate with the Ar sparge did not reach this plateau. Phosphate ion accumulates very slowly, indicating that demethylation of the dimethyl- and monomethyl- phosphate ions limits the rate of complete mineralization of dichlorvos.

Dichlorovinyl alcohol is unstable and will quickly tautomerize to dichloroacetaldehyde $\left(\mathrm{C}_{2} \mathrm{H}_{2} \mathrm{Cl}_{2} \mathrm{O}\right)$ (Hodgson and Casida 1962; Patil and Shingare 1994; Khandelwal and Wedzicha 1998). Dichloroacetaldehyde can react with hydroxyl radical to form dichloroacetic acid $\left(\mathrm{C}_{2} \mathrm{H}_{2} \mathrm{Cl}_{2} \mathrm{O}_{2}\right)$. The pKa of dichloroacetic acid is 1.3 (Bowden, Clegg et al. 1998), indicating that during the sonication experiments performed, it would be present primarily as the conjugate base, dichloroacetate ion $\left(\mathrm{C}_{2} \mathrm{H}_{2} \mathrm{Cl}_{2} \mathrm{O}^{-}\right)$. This ion will not partition into the bubble, so pyrolysis reactions are not possible. Dichloroacetate most likely hydrolyzes to a chlorohydroxyacetate intermediate $\left(\mathrm{C}_{2} \mathrm{H}_{2} \mathrm{ClO}_{3}{ }^{-}\right)$, which is very unstable (Diefallah, Ashy et al. 1981; Diefallah, Ghaly et al. 1982). This intermediate eliminates hydrochloric acid to form glyoxylate $\left(\mathrm{C}_{2} \mathrm{HO}_{3}{ }^{-}\right)$ (Diefallah, Ashy et al. 1981; Diefallah, Ghaly et al. 1982). The glyoxylate can then hydrolyze to formate and carbon dioxide (Carraway, Hoffman et al. 1994).

Chloride and formate ions as well as carbon dioxide are identified. The chloride ion rapidly accumulates for the $\mathrm{O}_{2}$ and $\mathrm{Ar} / \mathrm{O}_{2}$ sparge gases, nearly reaching the maximum theoretical concentration of $1.0 \times 10^{-3} \mathrm{M}$ after 1 hour of sonication. Again, the Ar sparge lags behind, indicating that a barrier to dechlorination exists. The lag of the Ar sparge gas is most evident with accumulation of formate. Almost no formate ion is produced when Ar is the sole sparge gas. Formate in all cases only accumulates and does not decrease. The slowness of formate transformation limits the rapidity of complete mineralization of dichlorvos.

The observed differences in the results of all compounds with varying sparge gas occur due to differences in the properties of the gases and their behavior in the cavitation bubble. The 
temperature of bubble collapse is dependent on the specific heat, thermal conductivity, and solubility of the sparge gas. However, impact of gases is complex, and it is difficult to quantitatively attribute particular trends to specific physico-chemical properties of the dissolved gases.

Dichlorvos quickly decomposes when exposed to ultrasonic irradiation. Increasing the output power increases dichlorvos concentration. The $\mathrm{Ar} / \mathrm{O}_{2}$ sparge gas with a power of $161 \mathrm{~W}$ gives optimum results. The reaction intermediates and products that have been identified are more innocuous than the parent compound, and much of the dichlorvos is mineralized within a short time of sonication. The mineralization of dichlorvos is limited by the mineralization of dimethyl phosphate and of formate. However, the presence of oxygen in solution helps to maximize the mineralization of dichlorvos and its intermediates.

\section{d. Sonochemical Reactor Design Factors}

In this section of the report, we describe exploration of ultrasound in flow-through reactor configurations, and under more realistic solution conditions, such as complex mixtures and actual surface water samples. We hypothesize that sonication can effectively destroy mixtures of organic compounds and will be viable in a realistic aqueous matrix. This paper reports the sonication of a mixture of chloropicrin, trichloroacetonitrile, and bromobenzene in a single-pass flow through reactor. Operative parameters such as flow rate, power intensity, and probe position were optimized. Batch experiments were carried out to investigate the efficiency of sonication at high COD levels and in a surface water matrix.

Most sonochemical reactors are operated as batch reactors, and are modeled as completely mixed reactors (Naidu, Rajan et al. 1994). Parallel plate reactors equipped with reservoirs are operated as batch re-circulating reactors (Hua, Hochemer et al. 1995; Thoma, Swofford et al. 1997). Horst has investigated the sonochemical reactor as an external module in a loop for easy scale-up (Horst, Chen et al. 1996). Gondrexon investigated completely mixed flow through reactors in series (Gondrexon, Renaudin et al. 1999). This investigation concerns a single flow-through reactor operated in single pass mode. This arrangement offers the potential advantages of simple installation and operation, and is straightforward to scale up.

Three model pollutants were chosen: chloropicrin $\left(\mathrm{CCl}_{3} \mathrm{NO}_{2}\right)$, trichloroacetonitrile $\left(\mathrm{C}_{2} \mathrm{Cl}_{3} \mathrm{~N}\right)$, and bromobenzene $\left(\mathrm{C}_{6} \mathrm{H}_{5} \mathrm{Br}\right)$. The three compounds are environmentally persistent and toxic (Freeman and Haugen 1998). Thus they represent persistent pollutants representative of agricultural, industrial and water treatment processes.

Experimental procedure

Detailed experimental procedures for this section of the report are contained in publication \#5 at the end of this progress report. Aqueous solutions were made with reagent grade water obtained from a Barnsted NANOpure ultra pure water system $\left(\mathrm{R}=18.3 \mathrm{M} \Omega \mathrm{cm}^{-1}\right)$ except for experiments with Wabash River water. One gallon of Wabash River water was taken from the surface of the Wabash River in Lafayette, Indiana. Solutions were prepared and sonicated within two hours after sampling from the Wabash. The chemical and physical characteristics of water were analyzed within two days after sampling; during that time the sealed water sample was stored at $4^{\circ} \mathrm{C}$. The temperature of the water was taken right after sampling.

The flow through reactor system was operated in single-pass mode. The solution was pumped from a 9.6 gallon stainless steel tank into the glass reactor (working volume $400 \mathrm{~mL}$ ), and then into a waste reservoir. Teflon and Viton tubing provided chemically inert connections between vessels. $20 \mathrm{kHz}$ ultrasound was provided via a probe system (VCX-400 Sonics and Materials 
Inc.) with a $1.3 \mathrm{~cm}$ diameter probe. The probe was immersed into solution to a depth of $2 \mathrm{~cm}$, and was placed in the center of the reactor unless stated otherwise. Batch experiments at $20 \mathrm{kHz}$ were performed in a water-jacketed glass cell $(200 \mathrm{~mL})$ using the same probe system detailed as above. Experiments at $358 \mathrm{kHz}$ were performed with a USW51 system (AlliedSignal Inc).

The target contaminants were analyzed with a Hewlett-Packard 5890 Gas Chromatograph equipped with an Electron Capture Detector (GC-ECD). Chloride, bromide, nitrite and nitrate ions were determined with a Dionex GP40 Ion Chromatograph equipped with an ASAI-4 column.

For the flow-through system, we report the sonication coefficient $\kappa=-\frac{\ln \left(\frac{C_{e f f}}{C_{\text {inf }}}\right)}{H R T}$ where $\mathrm{C}_{\text {inf }}$ and $\mathrm{C}_{\text {eff }}$ are the influent and effluent concentrations, respectively, and HRT is the average hydraulic resident time $\left(\frac{\text { Reactor volume }}{\text { Flow rate }}\right)$. Thus, the coefficient $\kappa$ has units of time ${ }^{-1}$. All reported values of $\kappa$ are the average of multiple runs under each set of conditions.

Results and discussion

A dynamic temperature profile was chosen in this investigation in order to simulate operations at a larger scale, when precise temperature control maybe more difficult or costly. The bulk temperature of solution increased during sonication by $3-12{ }^{\circ} \mathrm{C}$, depending on the flow-rate. The temperature profile was more stable at faster flow rates.

We first studied the sonication efficiency for mixed pollutants. Chloropicrin, trichloroacetonitrile, and bromobenzene were sonicated in mixtures and individually at $20 \mathrm{kHz}$, $30.8 \mathrm{~W} \mathrm{~cm}^{-2}$ in the batch reactor system. It was found that the pseudo first order rate constants $\left(\mathrm{min}^{-1}\right)$ for trichloroacetonitrile, chloropicrin, and bromobenzene were $4.7 \times 10^{-2} \pm 6.5 \times 10^{-4} \mathrm{~min}^{-}$ ${ }^{1}, 5.3 \times 10^{-2} \pm 4.4 \times 10^{-4} \mathrm{~min}^{-1}$ and $4.4 \times 10^{-2} \pm 7.5 \times 10^{-4} \mathrm{~min}^{-1}$ when sonicated individually. The rates were $4.4 \times 10^{-2} \pm 7.2 \times 10^{-4} \mathrm{~min}^{-1}, 5.0 \times 10^{-2} \pm 8.8 \times 10^{-4} \mathrm{~min}^{-1}$, and $4.1 \times 10^{-2} \pm 9.1 \times 10^{-4}$ $\min ^{-1}$ in a mixture. Sonication of mixtures did not significantly impact sonication decomposition rates, which is beneficial for actual treatment streams containing multiple pollutants. The mixture of the three target compounds was then used for all flow through experiments.

The next set of experiments involved sonication in a flow-through reactor. Several parameters were varied, including flow-rate. Higher flow rates allow for a greater treatment capacity under given conditions. Because a faster flow can enhance mass and heat transfer, we suspect that higher flow rates can enhance decomposition rates during sonication. Figure 2 illustrates the observed sonication coefficients for trichloroacetonitrile, chloropicrin, and bromobenzene during operation of the flow-through reactor different volumetric flow rates. As proposed, the sonication coefficients increased significantly with flow rate for all three compounds. The observed coefficient for bromobenzene at $34 \mathrm{~mL} \mathrm{~min}^{-1}$, is more than double of that at $4.4 \mathrm{~mL}$ $\mathrm{min}^{-1}$. The one exception to that trend is chloropicrin when sonicated with a flow-rate of $34 \mathrm{~mL}$ $\min ^{-1}$.

We further optimize the system by varying the position of ultrasonic probe. The length of the flow-through reactor from inlet to outlet was $15.2 \mathrm{~cm}$. We placed the ultrasonic probe at $1.0 \mathrm{~cm}$ (position 1), $7.6 \mathrm{~cm}$ (position 2), or $14.2 \mathrm{~cm}$ (position 3) downstream from the inlet. The flow rate at all positions was $34 \mathrm{~mL} \mathrm{~min}^{-1}$ and the sound intensity was $30.8 \mathrm{Wcm}^{-2}$. Figure 3 reports the sonication coefficients of trichloroacetonitrile, chloropicrin, and bromobenzene at different probe positions. Clearly, placement of position 1 results in the highest coefficients for 
all three compounds while placement of position 3 results in slowest rates. The difference in rates at the position 1 and position 3 was as high as $34 \%$ (chloropicrin).

We also studied the efficiency of sonication in complex real matrix by irradiating compounds dissolved in Wabash River water. A batch reactor was employed for more straightforward interpretation of the effects of a complex matrix. Table 1 indicates some physical and chemical characteristics of the sampled Wabash River water. The experimental results are shown in Figure 4. Clearly, the effectiveness of sonication in river water varies with the compound. A moderate decrease in decomposition rate is observed in some cases. The difference in sonication rates for the two samples may be caused by variable sample composition. Sample 2 has higher alkalinity $(172 \mathrm{ppm})$ and higher total organic carbon (TOC = $15.4 \mathrm{ppm}$ ) than sample 1 (alkalinity $=139 \mathrm{ppm}$ and $\mathrm{TOC}=11.6 \mathrm{ppm}$ ). Within the $\mathrm{pH}$ range of the experiment $(7-8)$, most alkalinity exists as bicarbonate, which is not an effective $\bullet \mathrm{OH}$ scavenger $\left(\mathrm{k}_{\mathrm{OH}-\mathrm{HCO} 3}\right.$ is $8.5 \times 10^{6} \mathrm{moleL}^{-1} \mathrm{~s}^{-1}$, (Buxton, Greenstock et al. 1988)). Furthermore, the difference in concentrations is slight; sample 2 contains $\sim 1.7 \mathrm{mM}$ bicarbonate and sample 1 contains $\sim 1.4 \mathrm{mM}$ bicarbonate. The more significant difference arises from the organic matter content, and the role of natural organic matter in sonochemical pathways is not well defined. However, the organic matter may possibly play a role in sequestering the target contaminating.

The COD load of the mixture is only $96 \mathrm{ppm}$, whereas many industrial wastewaters are in the COD range of thousands ppm (U.S.EPA 1998; U.S.EPA 1998). In order to study the viability of sonication for high strength treatment streams, we employed $0.1 \mathrm{mM}$ trichloroacetonitrile, $0.1 \mathrm{mM}$ chloropicrin, $5 \mathrm{mM}$ bromobenzene, and $0.1 \mathrm{M}$ methanol (employed to enhance the bromobenzene solubility). The total COD of the solution was $3470 \mathrm{ppm}$. The sonodegradation rates at $20 \mathrm{kHz}$ were much lower. The first order rate constants were $1.4 \times 10^{-2} \pm 9.8 \times 10^{-4}, 1.6$ $\times 10^{-2} \pm 7.7 \times 10^{-4}$, and $1.6 \times 10^{-2} \pm 1.2 \times 10^{-3} \mathrm{~min}^{-1}$ for trichloroacetonitrile, chloropicrin, and bromobenzene, respectively. The decrease in sonication rates maybe due to the high concentration of methanol. However, these decreased reaction rates are addressed by changing the ultrasonic frequency, as described below.

In order to optimize sonication in a complex matrix (river water, high organic solvent concentration), we changed the ultrasonic frequency. Previous experiments showed that sonochemical rates are much higher efficiency at $358 \mathrm{kHz}$ than at $20 \mathrm{kHz}$. Therefore, we investigated the sonodegradation rates for the three compounds at $358 \mathrm{kHz}$ and a total power of $160 \mathrm{~W}$ in a batch reactor. Figure 5 summarizes the results. Sonication is effective even with higher pollutant loads when the appropriate frequency is employed. At $358 \mathrm{kHz}, 73$ minutes are required to reduce the concentrations of the three compounds by $99 \%$.

The final series of experiments was meant to determine the extent of mineralization and release of halides during sonication. The chloride and bromide recovery ratio were calculated as follows:

$$
\text { X Recovery Rati } \frac{\left[\mathrm{x}^{-}\right]}{\left([\overline{\mathrm{M}}]_{\mathrm{i}}-[\mathrm{M}]_{\mathrm{f}}\right) \times \mathrm{n}}
$$

where $\left[\mathrm{X}^{-}\right]=$chloride or bromide ion concentration, mole $\mathrm{L}^{-1}$

$[\mathrm{M}]_{\mathrm{i}}=$ initial parent compound concentration, mole $\mathrm{L}^{-1}$

$[\mathrm{M}]_{\mathrm{f}}=$ final parent compound concentration, mole $\mathrm{L}^{-1}$

$\mathrm{n}=$ number of heteroatoms per molecule of substrate 
The recovery ratio of nitrogen as nitrite and nitrate was also examined. The nitrogen recovery ratio was calculated as the sum of nitrite and nitrate recovery ratio according to equation 6.

Measurements were performed for both a low concentration mixture $(10 \mu \mathrm{m}$ trichloroacetonitrile, chloropicrin, $0.5 \mathrm{mM}$ bromobenzene) and a high concentration mixture $(100 \mu \mathrm{m}$ trichloroacetonitrile, chloropicrin, $5 \mathrm{mM}$ bromobenzene with $0.1 \mathrm{M}$ methanol). After 30 minutes for the lower concentration mixture and 45 minutes for the higher concentration mixture, recovery ratios for chloride, bromide and nitrogen were $72 \pm 1 \%, 56 \pm 3 \%, 91 \pm 2 \%$. There was no significant difference in the recovery ratio between the low strength and high strength mixture. Measurements at extended sonication time (90 minutes) showed that bromide recovery increased to $69 \%$, but there was virtually no change in chloride and nitrogen recovery. The unrecovered portion of the halogens and of nitrogen are probably account for by organic intermediates which were not quantified in this study.

Conclusion

In conclusion, sonication is a viable method for pollutant treatment in complex or high strength systems. High flow rate accelerate sonication by lowering bulk temperature and increasing mass transfer. Setting ultrasonic probe close to inlet also enhances sonication by fully utilizing $\bullet \mathrm{OH}$ attack. Sonication has exhibits similar efficiency in river water as in reagent grade water. Higher concentration of solute with organic solvent decreased sonication rate, but can be overcome by increasing sound intensity or using higher sound frequency. Mass balance measurements show efficient recovery of chloride, nitrite and nitrate and bromide.

\section{e. Carbofuran Decomposition in the Near-Field Acoustical Processor}

The central objective of this research was to assess the efficacy of a novel ultrasonic reactor configuration for water pollution control. Carbofuran was chosen as a model contaminant. Thus, a primary aim was to measure the decomposition rate as well as inorganic nitrogen by-products under a variety of reactor conditions. A further objective was to study the hydrodynamic behavior of the NAP reactor by calculating Reynolds numbers and dispersion coefficients during ultrasonic irradiation.

Carbofuran (2,3-dihydro-2,2-dimethyl-7-benzofuranyl, $\mathrm{C}_{12} \mathrm{H}_{15} \mathrm{NO}_{3}$ ) is a broad-spectrum insecticide-nematicide. Formulations of carbofuran are used in agricultural applications worldwide, and in 1995, over five million pounds of carbofuran were applied to fields in the United States [Gianessi, 1995 \#58]. Carbofuran has been detected in the groundwater of at least seven states, and the United Sates Environmental Protection Agency (U. S. E. P. A.) has established a maximum contaminant level (MCL) of $0.04 \mathrm{mg} / \mathrm{L}$. Experimentally measured values of the organic carbon partition coefficient $\mathrm{K}_{\mathrm{oc}}$, which range from 14 to 160 , indicate that the compound will leach significantly into the aqueous phase. Thus, investigation of control methodologies should be focused on techniques that are effective in the aqueous phase.

A variety of physical and chemical procedures are employed for the removal of pesticides from water supplies. Numerous studies have been performed on carbofuran degradation with ozone, ultraviolet (UV) irradiation and hydrogen peroxide. In this section of the report, we report the sonochemical destruction of carbofuran and investigate the hydrodynamics of a parallel-plate near-field acoustical processor (NAP) reactor, operating at 16 and $20 \mathrm{kHz}$. Experimental Methods

Details of experimental methods and measurements are included in publication \#3, at the end of this progress report. All experiments were performed at a total power input of 1800 Watts 
(W) and a power to area ratio (power intensity) of $1.22 \mathrm{~W} \mathrm{~cm}^{-2}$. However, the reactor gap width (the space between the two plates) was varied between $1 / 2$ inch $(1.27 \mathrm{~cm}), 1 / 8$ inch $(0.318 \mathrm{~cm})$ and $1 / 16$ inch $(0.159 \mathrm{~cm})$ which corresponds to sonoactive volumes of $1089 \mathrm{~mL}, 426 \mathrm{~mL}$ and $324 \mathrm{~mL}$. The power to volume ratios (power density), therefore, varied from $1.65 \mathrm{~W} / \mathrm{mL}$ to 5.55 $\mathrm{W} / \mathrm{mL}$. The initial bulk solute concentration was either $25 \mu \mathrm{M}$ or $130 \mu \mathrm{M}$, and Argon, or a mixture of Argon:Oxygen (4:1 v/v) was used to saturate the sonicated solutions.

In a near-field acoustical processor (Advanced Sonic Processing Systems) the vibrational energy is transferred to the reaction mixture via two parallel stainless steel plates that are bolted together. Each plate is driven by magnetostrictive transducers. Total power input into the two frequency-generating units was maintained at 1800 Watts. Throughout the study, a volumetric flow rate of $3.2 \mathrm{~L} / \mathrm{min}$ was maintained.

The quantification of carbofuran was performed with a Waters liquid chromatograph (model 600 Controller, model 717 Plus Autosampler) equipped with a photodiode array detector (Waters 991) operating at a wavelength of $\lambda=278 \mathrm{~nm}$. The production of nitrite $\left(\mathrm{NO}_{2}^{-}\right)$and nitrate $\left(\mathrm{NO}_{3}^{-}\right)$were measured with a Dionex Ion Chromatograph GP40/4400 (IC) with a conductivity detector (Dionex CD20).

Sodium chloride was used as a conservative tracer to characterize the reactor hydrodynamics. The tests were run during ultrasonic irradiation $(\mathrm{P}=1800 \mathrm{~W})$ as well as without irradiation $(\mathrm{P}=0 \mathrm{~W})$. The tracer was introduced into the NAP during operation in the flowthrough mode $(\mathrm{Q}=3.2 \mathrm{~L} / \mathrm{min})$, and the temporal distribution of $\mathrm{NaCl}$ was monitored with a conductivity meter (Cole-Parmer, Model \#19820-10).

Results and Discussion

Baseline tests were performed to determine any loss of carbofuran not due to sonication. The tests were conducted under identical conditions as the actual sonication experiments except that the power output was zero; the results indicated that carbofuran was not lost through adsorption or volatization from the system.

The actual run time can be converted into an effective sonication time by:

$$
\mathrm{t}_{\text {effective }}=\frac{\mathrm{V}_{\mathrm{R}} \cdot \mathrm{t}_{\text {run }}}{\mathrm{V}_{\mathrm{NAP}}+\mathrm{V}_{\mathrm{R}}}
$$

where $\mathrm{V}_{\mathrm{NAP}}=$ volume of the NAP reactor, $\mathrm{V}_{\mathrm{R}}=$ volume of the reservoir, $\mathrm{t}_{\mathrm{run}}=$ total run time, $\mathrm{t}_{\text {effective }}=$ effective run time. The justification for using this conversion factor is fully developed in an article by. The effective sonication time scale was employed to determine the observed decomposition rate constant for each experiment.

The estimated pseudo first-order rate constants for different experimental conditions along with the associated standard error, and $\mathrm{R}$ squared (coefficient of determination) values are summarized in Table 1. The half-lives for the sonolytic decomposition of carbofuran are also shown and range from $9.3 \mathrm{~min}$ to $103.9 \mathrm{~min}$.

Previous studies focused on the dependence of the rate constant on the power per unit area (sound intensity). However, the power per unit volume is also important for optimizing decomposition rates. In this study, the sound intensity was maintained at a constant value ( $\mathrm{I}=$ $1.22 \mathrm{~W} \mathrm{~cm}^{-2}$ ), while the power per unit volume was varied. Figure 1 compares the observed first-order kinetics for increasing power per unit volume. In each case, the psuedo - first order rate constant decreased when the solute concentration increased. This maybe due to mass transfer considerations or reaction by-product build-up. Faster degradation rates at higher power densities were observed because the number of bubbles in solution depends upon the power 
input. Sonochemical reactions occur within or near cavitation bubbles, and therefore, a larger number of bubbles present in solution enhances observed decomposition kinetics.

The effect of initial bulk concentrations was determined as well. For every power density, the pseudo-first order rate coefficient decreased with increasing solute concentration. These findings can be interpreted by considering how the parent compound transforms during sonolysis, mass transport limitations associated with carbofuran transport to the bubble interface, and the build-up of decomposition by-products in solution. Carbofuran is characterized by a relatively high melting point $\left(150-153^{\circ} \mathrm{C}\right)$, a low vapor pressure $\left(8.8 \times 10^{-6} \mathrm{~mm} \mathrm{Hg}\right)$ and a low Henry's Constant $\left(3.9 \times 10^{-9} \mathrm{~atm} \mathrm{m^{3 }} / \mathrm{mole}\right)$. Thus, the molecule will not undergo reaction within the vapor phase of the bubble. Carbofuran most likely reacts at the bubble interface, or within the bulk solution. Free-radicals and oxidants which are produced with in the cavitation bubble therefore must diffuse through the interface in order to react with carbofuran remaining in the bulk solution. Thus, the observed reaction rates should be correlated to the available surface area of the cavitation bubbles. Typical decomposition products observed during sonolysis of organic compounds often include short chain organic acids, which are much more soluble and less volatile than the parent compound. These compounds will certainly compete in the aqueous phase and at the bubble interface for free-radicals and other oxidants generated during cavitation. At higher initital concentrations, obviously, the accumulation of by products will be greater, thus representing more competition with the parent compound. Product build-up and mass transfer play important roles in limiting sonolytic decomposition.

The dissolved gas impacted carbofuran decomposition rates. Mixtures of sparge gases can optimize sonolytic reaction rates because the chemical reactivity at a cavitation site is determined by the final temperature within the bubble during collapse as well as the nature of the oxidizing species produced. In the presence of $\mathrm{Ar}$, higher final temperatures result within the bubble. When $\mathrm{O}_{2}$ is employed, a greater variety of oxidizing species can form, but the effective temperature upon bubble collapse will be lower. Thorough discussions of the free-radical pathways in cavitation chemistry are available. Combining $\mathrm{Ar}$ and $\mathrm{O}_{2}$ in the proper ratio results in optimal decomposition kinetics. Under these conditions, higher final temperatures and pressures at bubble collapse along with higher concentrations of oxidizing species can be achieved. The authors evaluated the effect of $\mathrm{Ar}$ and an $\mathrm{Ar} / \mathrm{O}_{2}$ mixture during sonolysis of carbofuran. Figure 2 demonstrates the change in observed first-order kinetics as a function of sparge gas. At the power density of $1.65 \mathrm{~W} / \mathrm{mL}$, the composition of the gas did not significantly influence the observed kinetics. However, at the higher power densities, the degradation of the pollutant occurred more rapidly in the solution saturated with a 4:1 (v/v) $\mathrm{Ar} / \mathrm{O}_{2}$ mixture.

In addition to kinetic studies, the authors investigated the nitrogen balances during carbofuran decomposition. Detection of nitrite $\left(\mathrm{NO}_{2}^{-}\right)$and nitrate $\left(\mathrm{NO}_{3}{ }^{-}\right)$during sonolysis of other nitrogen-containing compounds has been reported. The initial and final amount of nitrogen from carbofuran was calculated from the HPLC data. The concentrations of nitrite and nitrate in solution were determined by ion chromatography and reported in terms of the amount of nitrogen the solution contained. The balance of nitrogen was defined by:

carbofuran- $\mathrm{N}]_{\text {initial }}=[\text { carbofuran- } \mathrm{N}]_{\mathrm{t}}+\left[\mathrm{NO}_{2}-\mathrm{N}\right]_{\mathrm{t}}+\left[\mathrm{NO}_{3}-\mathrm{N}\right]_{\mathrm{t}}+[\text { unknown- } \mathrm{N}]_{\mathrm{t}}$

where $[\text { carbofuran }-\mathrm{N}]_{\text {initial }}=$ nitrogen atoms present as carbofuran, based on initial carbofuran concentration and $[\text { carbofuran- }-\mathrm{N}]_{\mathrm{t}}=$ nitrogen atoms present as carbofuran at time, t. $\left[\mathrm{NO}_{2}-\mathrm{N}\right]$ and $\left[\mathrm{NO}_{3}-\mathrm{N}\right]=$ nitrogen atoms as nitrite and nitrate ions at time, $\mathrm{t}$, and [unknown-N $]_{\mathrm{t}}=$ nitrogen atoms for which the speciation is unknown. Table 5 contains final values for the observed concentrations of nitrite and nitrate at the conclusion of irradiating a $130 \mu \mathrm{M}$ solution saturated 
with an $\mathrm{Ar} / \mathrm{O}_{2}$ mixture. $91 \%$ of the nitrogen is accounted for and [unknown-N] $]_{\mathrm{t}}=11 \mu \mathrm{M}$. Furthermore, $86 \%$ of the carbofuran which was destroyed was converted into either nitrite or nitrate.

Material balance, macrotransport, and chemical reaction rate principles can be brought together to describe reactor performance. In most systems of practical concern, macrotransport of components occurs by a combination of advection and dispersion. That is, components are carried along by the bulk flow while being dispersed by momentum exchange of fluid elements due to turbulence.

To determine the character of fluid flow, and thus of cocurrent advective transport of the dissolved substances in the NAP reactor, the Reynolds number for different experimental conditions was calculated. In general, the larger the Reynolds number, the more the character of flow will be determined by turbulence. Since turbulence is a factor that can influence dispersive transport, the amount of turbulence at the given experimental conditions was of interest.

The Reynolds number was determined by Equation 5:

$$
\operatorname{Re}=\frac{\rho \mathrm{vd}_{\mathrm{h}}}{\mu}
$$

where ${ }_{-}=$density of the fluid, $\ldots=$ viscosity of the fluid, $v_{=}=$velocity, $d_{h}=$ hydrodynamic diameter, $\mathrm{w}=$ flow channel width, and $\mathrm{h}=$ flow channel height. Figure 3 illustrates the relationship between Reynolds number, flow rate, and gap width for the NAP reactor. For the actual run conditions of $3.2 \mathrm{~L} \mathrm{~min}^{-1}$ and gap widths of $1 / 2$ inch $(1.27 \mathrm{~cm}), 1 / 8$ inch $(0.318 \mathrm{~cm})$ and $1 / 16$ inch $(0.159 \mathrm{~cm})$, the calculated Reynolds numbers of 1178, 1310, and 1332, respectively, indicate the presence of laminar flow in the NAP-reactor.

For the purpose of designing a scale-up version of the reactor system, it is also necessary to quantify deviations in the behavior of the NAP-reactor from that of ideal reactors. The boundaries of "ideal" reactor behavior are assumed to be either complete (perfect) mixing or no intermixing (plug-flow) of fluid elements. The deviation in behavior of the NAP-reactor can be determined by characterizing its residence time distribution (RTD) which is done experimentally by means of tracer tests.

Tracer tests were performed with and without sonication at gap -widths of $1 / 8$ and $1 / 16$ inch. Figure 4 shows the response curves to a step input of tracer to the reactor (1/8 inch spacer) influent during operation at $1800 \mathrm{~W}$ or at $0.0 \mathrm{~W}$. The data were analyzed and used to calculate the Paclet number for each test. The Peclet number, Pe, represents the ratio of advective to dispersive (longitudinal) mass transport in a tubular reactor:

$$
\mathrm{Pe}=\frac{\mathrm{vL}}{\mathrm{D}}
$$

where $\mathrm{v}=$ velocity, $\mathrm{L}=$ length of the flow channel and $\mathrm{D}=$ dispersion coefficient. Equation 6 was then used to calculate the dispersion coefficient, D, which characterizes the degree of backmixing during flow. As the Peclet number increases, the dispersion coefficient decreases, and the reactor approaches plug flow. Table 6 summarizes the calculated dispersion coefficients for different reactor configurations. The calculated dispersion coefficients indicate intermediate dispersion in the reactor. However, no significant difference between the two gap widths was observed.

Conclusions

The decomposition of carbofuran follows first-order kinetics, and faster degradation rates are observed at higher power densities (power per unit volume), lower initial concentrations of carbofuran, and when sparging with an $\mathrm{Ar} / \mathrm{O}_{2}$ mixture. Nitrite and nitrate were detected in 
sonicated solution, and the inorganic nitrogen recovery is $86 \%$. Calculated Reynolds numbers for the experimental conditions indicate the presence of laminar flow in the NAP reactor, and tracer tests suggest an intermediate amount of dispersion in the NAP-reactor.

\section{$f$. The Impact of Particulates on Sonochemical Treatment}

The sonodegradation of bromobenzene was studied in the presence of different solids in water. We examined the feasibility of ultrasound to treat wastewater with solids, and the changes of solid properties by ultrasound. Three diameters $(10 \mathrm{~nm}, 15 \mu \mathrm{m}, 35 \mu \mathrm{m})$ and two particle types (silica and polyaromatic) were investigated over a range of concentrations ( 0.14 to $\left.14 \mathrm{gL}^{-1}\right)$. The pseudo first order degradation rate for $0.5 \mathrm{mM}$ bromobenzene without solid was $0.044 \pm 0.00075 \mathrm{~min}^{-1}$ at $20 \mathrm{kHz}$ and $30.8 \mathrm{Wcm}^{-2}$. Sonication was not impacted by very fine particle $(10 \mathrm{~nm}$ silica). $15 \mu \mathrm{m}$ silica decreased sonication rates only slightly $(<7 \%)$ even at concentration of $10 \mathrm{gL}^{-1}$. 35 organic polyaromatic particles demonstrated a more significant impact; the highest reduction $\left(26.7 \%\right.$ ) occurred at a solid concentration of $14 \mathrm{gL}^{-1}$. These results demonstrate that sonication is effective in presence of various solid particles. This is significant for application of ultrasound to treatment streams containing solid particles. Sonication effectively broke solids into smaller ones $(35 \mu \mathrm{m}-1.05 \mu \mathrm{m}$, and $15 \mu \mathrm{m}-0.75 \mu \mathrm{m})$. Ultrasound quickly desorbed bromobenzene from the solids.

\section{g. The Impact of Ultrasonic Frequency on Aqueous Sonoluminescence and Sonochemistry}

A comprehensive investigation of ultrasonic frequency and its role in sonochemical activity and sonoluminescence (SL) has been performed. SL spectra and intensity were examined at four frequencies $(205,358,618$, and $1071 \mathrm{kHz})$ and in the presence of varying Argon and Oxygen saturation ratios. A series of high-energy reactions induced by the extreme temperatures and pressures obtained within a microbubble during acoustic cavitation contribute to the broad continuum characteristic of SL spectra. Chemical reactivity was also measured at all four frequencies. 1,4-Dioxane decomposition and hydrogen peroxide formation were chosen as representative sonochemical processes. $358 \mathrm{kHz}$ was the optimal frequency for maximum SL intensity and chemical reaction rates. The impact of a hydroxyl radical scavenger, bicarbonate ion, on SL intensity and $\mathrm{H}_{2} \mathrm{O}_{2}$ formation was also examined. Results from this investigation indicate that non-linear bubble implosions play a more significant role at lower frequencies whereas higher species flux rates influence chemical reactivity at higher frequencies.

Ultrapure water $\left(\mathrm{R}=18 \mathrm{M} \Omega \mathrm{cm}^{-1}\right)$ was obtained through a Barnstead NANOpure Ultrapure water system. Reagent grade potassium biphthalate (J.T. Baker, Inc.), potassium iodide (KI) (VWR Scientific), ammonium molybdate (Fisher Scientific), 1,4-dioxane (Sigma), ethylbenzene (Aldrich), and GC resolve grade hexane and methylene chloride (Fisher Scientific) were used as received. Fresh solutions of $1.0 \mathrm{mM} \mathrm{1,4-dioxane}$ were used for each study. The experimental procedure for determining 1,4-dioxane decomposition rates is discussed elsewhere. 20

Methods. A Cornerstone 130 Monochromator (Oriel Instruments) equipped with a 1200grooves/mm grating blazed at $250 \mathrm{~nm}$ and a resolution of $3 \mathrm{~nm}$ was used for medium-resolution studies of SL. The detector consisted of an Oriel Instruments side-on photomultiplier tube (PMT) powered by a 2000 VDC power supply and controlled by an OPM Multifunction Optical 
Power Meter (Oriel Instruments). TRAC32 Data Acquisition Software (Oriel Instruments) was used for spectral collection and analysis. All SL emission data was collected from $200 \mathrm{~nm}-650$ $\mathrm{nm}$ and the intensities reported are from the average of three spectral analyses. The monochromater was spectrally calibrated with a NIST-traceable standard Mercury (Argon) lamp. The spectral response was calibrated using a QTH source (Oriel Instruments) in the range 200 $600 \mathrm{~nm}$. The monochromator was removed when determining emission intensity, thereby allowing for more sensitive detection measurements to be made with the PMT.

SL and sonolytic experiments were performed with an AlliedSignal URS 1000 Ultrasonic Transducer powered by an Allied Signal R/F generator LVG 60 (256 W maximum output). The instrumentation is shown in Fig. 1. The effect of frequency on SL and chemical reactivity was investigated using the same transducer and reactor system for each experiment to maintain consistent power/area and power/volume ratios. Four ultrasonic frequencies were employed during the experiments $(205,358,618$, and $1071 \mathrm{kHz})$. The active acoustical vibration area of the transducer was $25 \mathrm{~cm}^{2}$ and the output power of the generator (indicated on the instrument) was $128 \mathrm{~W}$. Therefore, the effective transducer intensity during each experiment was $5.1 \mathrm{~W} / \mathrm{cm}^{2}$ (power/vibration area). The irradiated aqueous solutions were contained in a custom designed water jacketed quartz reactor with an optical quartz interface (Kontes Custom Glass) connected to a circulating cooling bath (Fisher Scientific). While the maximum volume for the glass reactor was $700 \mathrm{~mL}$, the sonicated volume for each experiment was $500 \mathrm{~mL}$.

Temperature profiles of the bulk liquid were taken to determine the equivalent amount of energy input at each frequency and are shown in Table 1. The energy delivered into the system was within five percent for all frequencies.

A series of spectra were obtained for the light emission of aqueous solutions under a variety of ultrasonic frequency and sparge gas conditions. With the exception of $1071 \mathrm{kHz}$, the spectrum at each frequency exhibits the emergence of a broad continuum beginning at $200 \mathrm{~nm}$ and continuing through $500 \mathrm{~nm}$ while peaking at approximately $300 \mathrm{~nm}$. A frequency of 358 $\mathrm{kHz}$ yields the broadest spectrum and greatest intensity at $300 \mathrm{~nm}$, followed by 205 and $618 \mathrm{kHz}$. The spectrum for $1071 \mathrm{kHz}$ appears diminished relative to the other three frequencies but exhibits similar features that are apparent when examined at a different scale. Spectra were also taken of luminescence in the presence of different mixtures of $\mathrm{Ar}$ and $\mathrm{O}_{2}$. The frequency used for these experiments was $358 \mathrm{kHz}$. The decrease in signal intensity follows the decrease in percentage of Ar. The features of each spectrum at different sparge ratios are analogous although the intensities differ. There was virtually no spectral emission observed in the presence of $100 \% \mathrm{O}_{2}$. The spectra at various sparge gas ratios at $358 \mathrm{kHz}$ vary primarily in total intensity and not in distinctive spectral features.

Describing acoustic cavitation conditions at different frequencies during ultrasonic irradiation is a difficult task. Important processes and variables include mass transfer through the gas-liquid interface, effective cavitation events per unit time, resonant bubble size, deformation of the interface during bubble collapse, and temperatures within the microcavity. This investigation contributes to explanations of the broad spectra produced at different frequencies. Oxygen appears to be a significant quencher of these luminescence reactions. Nonlinear bubble implosions play a more significant role at lower frequencies whereas higher species flux rates influence chemical reactivity at higher frequencies. Finally, the optimal frequency for $\mathrm{SL}$ and chemical reaction rates is $358 \mathrm{kHz}$. 
Tables

Table 1: Physico-Chemical Properties of Selected PCBs

\begin{tabular}{|l|l|l|l|l|l|}
\hline Congener & $\begin{array}{l}\text { Molecular weight } \\
\left(\mathrm{g} \mathrm{mol}^{-1}\right)\end{array}$ & $\begin{array}{l}\text { Log P } \\
(\mathrm{atm})\end{array}$ & $\begin{array}{l}\text { Log } \mathrm{H} \\
\left(\mathrm{L} \mathrm{atm} \mathrm{mol}^{-1}\right)\end{array}$ & $\underline{\underline{\log }_{\text {ow }}}$ & $\begin{array}{l}\text { Log S } \\
\left(\mathrm{mol} \mathrm{L}^{-1}\right)\end{array}$ \\
\hline 2-PCB & $1.887 \times 10^{2}$ & -4.66 & $-9.0 \times 10^{-2}$ & 4.53 & -4.63 \\
\hline $4-\mathrm{PCB}$ & $1.887 \times 10^{2}$ & -5.33 & $-6.3 \times 10^{-1}$ & 4.40 & -5.33 \\
\hline $245-\mathrm{PCB}$ & $2.575 \times 10^{2}$ & -6.95 & $-6.9 \times 10^{-1}$ & 5.78 & -6.45 \\
\hline
\end{tabular}

*P: vapor pressure [Schwarzenbach, 1993 \#284]; H: Henry's constant; Kow: octanolwater distribution constant; S: aqueous solubility (Nirmalakhandan and Speece 1989).

Table 2: Observed Rate Constants for Sonolytic

PCB Destruction at $20 \mathrm{kHz}$

\begin{tabular}{|c|c|c|c|}
\hline PCB Congener & $\begin{array}{l}\text { Initial } \\
\text { Concentration } \\
\left.\qquad \mu \mathrm{mol} \mathrm{L}{ }^{-1}\right] \\
\mu\end{array}$ & $\begin{array}{l}\text { First order rate constant } \\
{\left[\text { second }^{-1}\right]}\end{array}$ & $\begin{array}{l}\text { Linear } \\
\text { regression } \\
\text { coefficient } \mathrm{R}^{2}\end{array}$ \\
\hline 2-PCB & 4.6 & $2.1 \times 10^{-3} \pm 2.8 \times 10^{-5}$ & $9.8 \times 10^{-1}$ \\
\hline 4-PCB & 5.4 & $1.6 \times 10^{-3} \pm 3.4 \times 10^{-5}$ & $9.6 \times 10^{-1}$ \\
\hline $2,4,5-\mathrm{PCB}$ & $7.6 \times 10^{-2}$ & $2.6 \times 10^{-3} \pm 9.4 \times 10^{-5}$ & $9.4 \times 10^{-1}$ \\
\hline
\end{tabular}

Table 3. Observed First Order Rate Constants for Sonication of Dichlorvos

\begin{tabular}{|l|l|l|l|}
\hline Gas Sparge & Acoustic Power (Watts) & Rate Constant $\left(\mathrm{min}^{-1}\right)$ & $\mathrm{R}^{2}$ value \\
\hline Argon & 86 & $0.018 \pm 0.001$ & 0.99 \\
\hline Argon & 124 & $0.025 \pm 0.002$ & 0.99 \\
\hline Argon & 161 & $0.037 \pm 0.002$ & 0.99 \\
\hline Oxygen & 161 & $0.031 \pm 0.003$ & 0.97 \\
\hline Argon / Oxygen (60/40 v/v) & 161 & $0.079 \pm 0.005$ & 0.98 \\
\hline
\end{tabular}

Table 4: Selected physical and chemical characteristics of sampled Wabash River water from Lafayette, Indiana

\begin{tabular}{|c|c|c|c|c|c|c|}
\hline Sample & Temperature & $\mathrm{pH}$ & Alkalinity & TSS & TDS & TOC \\
\hline 1 & $22.1^{\circ} \mathrm{C}$ & 7.21 & $\begin{array}{l}139 \mathrm{mg} / \mathrm{L} \\
\mathrm{CaCO}_{3}\end{array}$ & $375 \mathrm{mg} / \mathrm{L}$ & $145 \mathrm{mg} / \mathrm{L}$ & $11.6 \mathrm{mg} / \mathrm{L}$ \\
\hline 2 & $14^{\circ} \mathrm{C}$ & 7.06 & $\begin{array}{l}172 \mathrm{CaCO}_{3} \\
\mathrm{Cag} / \mathrm{L}\end{array}$ & $330 \mathrm{mg} / \mathrm{L}$ & $135 \mathrm{mg} / \mathrm{L}$ & $15.4 \mathrm{mg} / \mathrm{L}$ \\
\hline
\end{tabular}


Table 5: Rate constants and regression data from kinetics experiments

\begin{tabular}{|l|l|l|l|l|l|l|l|l|}
\hline \multicolumn{3}{|l|}{ Conditions } & $\begin{array}{l}\text { Pseudo First- } \\
\text { Order Rate } \\
\text { Constant }\end{array}$ & $\begin{array}{l}\text { Regression } \\
\text { Data }\end{array}$ & $\begin{array}{l}\text { Half- } \\
\text { life }\end{array}$ & $\begin{array}{l}\text { Expt. } \\
\text { No. }\end{array}$ \\
\hline $\begin{array}{l}\text { P/V } \\
{[\mathrm{W} / \mathrm{mL}]}\end{array}$ & $\begin{array}{l}\text { Gap } \\
\text { [inch] }\end{array}$ & $\begin{array}{l}\text { Co } \\
{[\mathrm{M}]}\end{array}$ & $\mathrm{Gas}$ & $\mathrm{k},\left[\mathrm{min}^{-1}\right]$ & $\begin{array}{l}\text { Standard } \\
\text { error }\end{array}$ & $\mathrm{R}^{2}$ & $\mathrm{t}_{\frac{1}{2},}, \mathrm{mir}$ \\
\hline 1.65 & $1 / 2$ & 25.4 & $\mathrm{Ar}$ & 0.0167 & 0.0002 & 0.997 & 41.5 & 1 \\
\hline 1.65 & $1 / 2$ & 24.9 & $\mathrm{Ar} / \mathrm{O}_{2}$ & 0.0156 & 0.0001 & 0.998 & 44.4 & 2 \\
\hline 1.65 & $1 / 2$ & 128.1 & $\mathrm{Ar}$ & 0.00667 & 0.00001 & 0.998 & 103.9 & 3 \\
\hline 1.65 & $1 / 2$ & 131.3 & $\mathrm{Ar}$ & 0.00734 & 0.0001 & 0.996 & 94.4 & 4 \\
\hline 1.65 & $1 / 2$ & 129.0 & $\mathrm{Ar} / \mathrm{O}_{2}$ & 0.00736 & 0.0001 & 0.998 & 94.2 & 5 \\
\hline 4.22 & $1 / 8$ & 25.2 & $\mathrm{Ar}$ & 0.0373 & 0.001 & 0.988 & 18.6 & 6 \\
\hline 4.22 & $1 / 8$ & 25.2 & $\mathrm{Ar} / \mathrm{O}_{2}$ & 0.0489 & 0.0005 & 0.998 & 14.2 & 7 \\
\hline 4.22 & $1 / 8$ & 128.3 & $\mathrm{Ar} / \mathrm{O}_{2}$ & 0.0243 & 0.0003 & 0.997 & 28.5 & 8 \\
\hline 5.55 & $1 / 16$ & 25.2 & $\mathrm{Ar}$ & 0.0622 & 0.0006 & 0.999 & 11.1 & 9 \\
\hline 5.55 & $1 / 16$ & 25.0 & $\mathrm{Ar} / \mathrm{O}_{2}$ & 0.0749 & 0.0008 & 0.998 & 9.3 & 10 \\
\hline 5.55 & $1 / 16$ & 129.8 & $\mathrm{Ar}$ & 0.0323 & 0.0002 & 0.999 & 21.5 & 11 \\
\hline 5.55 & $1 / 16$ & 130.5 & $\mathrm{Ar} / \mathrm{O}_{2}$ & 0.0369 & 0.0006 & 0.997 & 18.8 & 12 \\
\hline 5.55 & $1 / 16$ & 130.3 & $\mathrm{Ar} / \mathrm{O}_{2}$ & 0.0388 & 0.0002 & 0.999 & 17.9 & 13 \\
\hline
\end{tabular}

Table 6: Final distribution of nitrogen atoms in a sonicated solution of carbofuran

\begin{tabular}{|c|ll|lc|}
\hline species & $\begin{array}{l}\text { Initial } \\
\text { M }\end{array}$ & concentration, & $\begin{array}{l}\text { Final } \\
\text { M }\end{array}$ & concentration, \\
\hline carbofuran & & 131 & & 51 \\
\hline Nitrite & & ND & & 40 \\
\hline Nitrate & & ND & 29 \\
\hline
\end{tabular}

*ND indicates that the ion was not detected. 
Table 7: Reynolds numbers as a function of flow rate and gap width

\begin{tabular}{|l|l|l|l|l|l|l|l|l|l|l|l|l|}
\hline & \multicolumn{10}{|l|}{ Flow Rate, $\mathrm{mL} \mathrm{min}^{-1}$} \\
\cline { 2 - 13 } & & 230 & 790 & 1600 & 2380 & 3180 & 3970 & 4770 & 5560 & 6360 & 7150 & 7950 \\
\cline { 2 - 13 } Gap & $1 / 16$ & 96 & 331 & 670 & 997 & 1332 & 1663 & 1999 & 2330 & 2665 & 2996 & 3331 \\
Width, & $1 / 8$ & 95 & 325 & 659 & 980 & 1310 & 1635 & 1964 & 2290 & 2619 & 2944 & 3274 \\
(in) & $1 / 2$ & 85 & 293 & 593 & 882 & 1178 & 1471 & 1767 & 2060 & 2356 & 2649 & 2946 \\
\hline
\end{tabular}

During carbofuran destruction studies, the NAP reactor was operated at a flow rate of $3.2 \mathrm{~L} \mathrm{~min}^{-1}$ $\left(192 \mathrm{~L} \mathrm{hr}^{-1}\right)$. Spacer thicknesses of $1 / 2$ inch $(1.27 \mathrm{~cm}), 1 / 8$ inch $(0.318 \mathrm{~cm})$ and $1 / 16$ inch $(0.159$ $\mathrm{cm}$ ) corresponded to sonoactive volumes of $1089 \mathrm{~mL}, 426 \mathrm{~mL}$ and $324 \mathrm{~mL}$, respectively.

Table 8: Calculated dispersion coefficients, D

\begin{tabular}{|l|c|c|c|c|}
\hline $\begin{array}{l}\text { Gap width } \\
\text { [inch] } \\
(\mathrm{cm})\end{array}$ & $\begin{array}{c}1 / 8 \\
(0.318)\end{array}$ & $\begin{array}{c}1 / 8 \\
(0.318)\end{array}$ & $\begin{array}{c}1 / 16 \\
(0.159)\end{array}$ & $\begin{array}{c}1 / 16 \\
(0.159)\end{array}$ \\
\hline Power [W] & 0 & 1800 & 0 & 1800 \\
\hline Peclet number & 22 & 31 & 26 & 36 \\
\hline D [cm $\left.\mathrm{min}^{-1}\right]$ & 3350 & 2350 & 2650 & 2610 \\
\hline D/vL & 0.046 & 0.033 & 0.038 & 0.028 \\
\hline
\end{tabular}




\section{Figures}

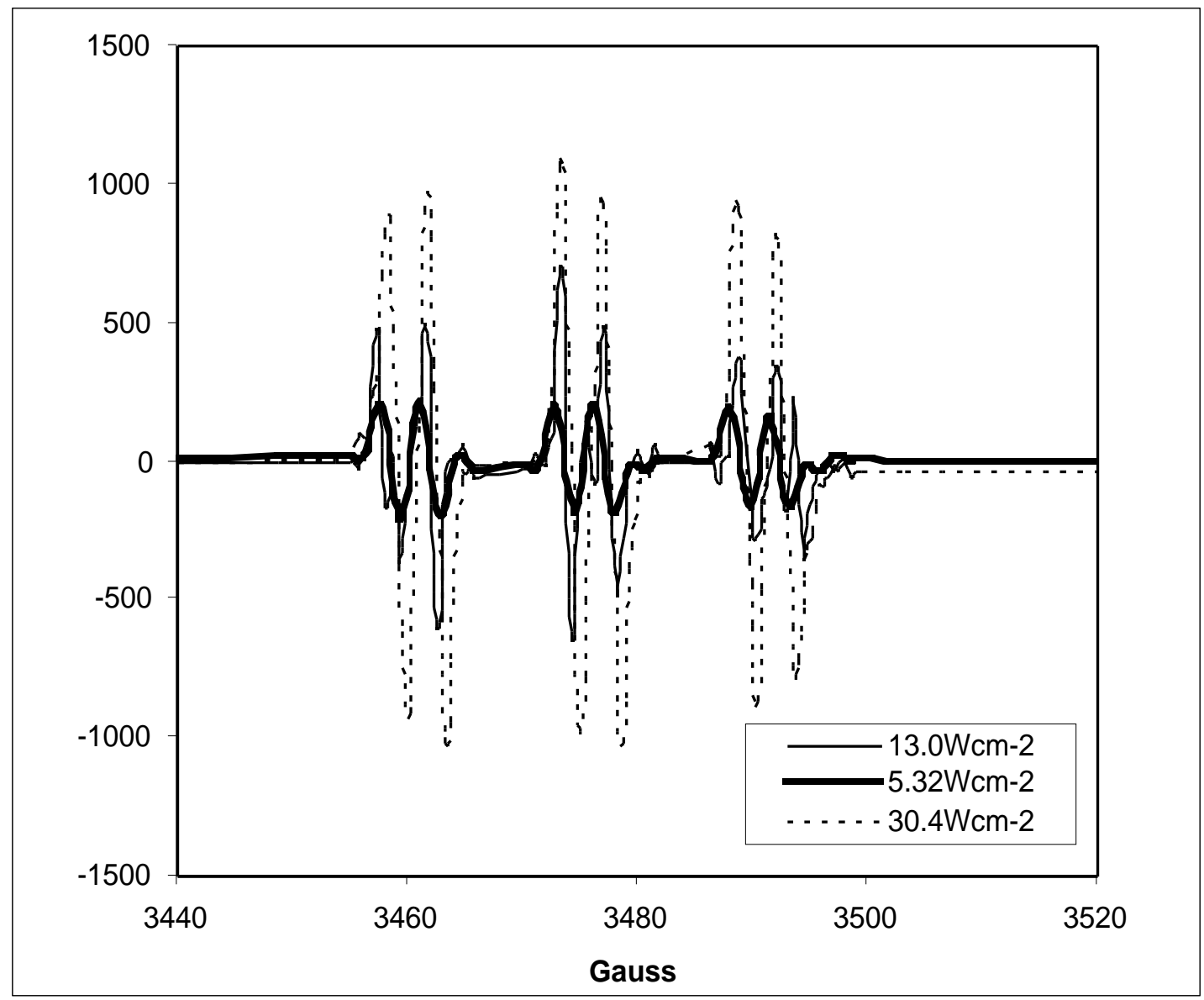

Fig. 1: First - derivative ESR spectrum indicating the accumulation of PBN-phenyl after 10 minutes of sonicating an Ar-saturated solution of 2-PCB $(4.6 \mu \mathrm{M})$ at $20 \mathrm{kHz}$ and varying sound intensities. 


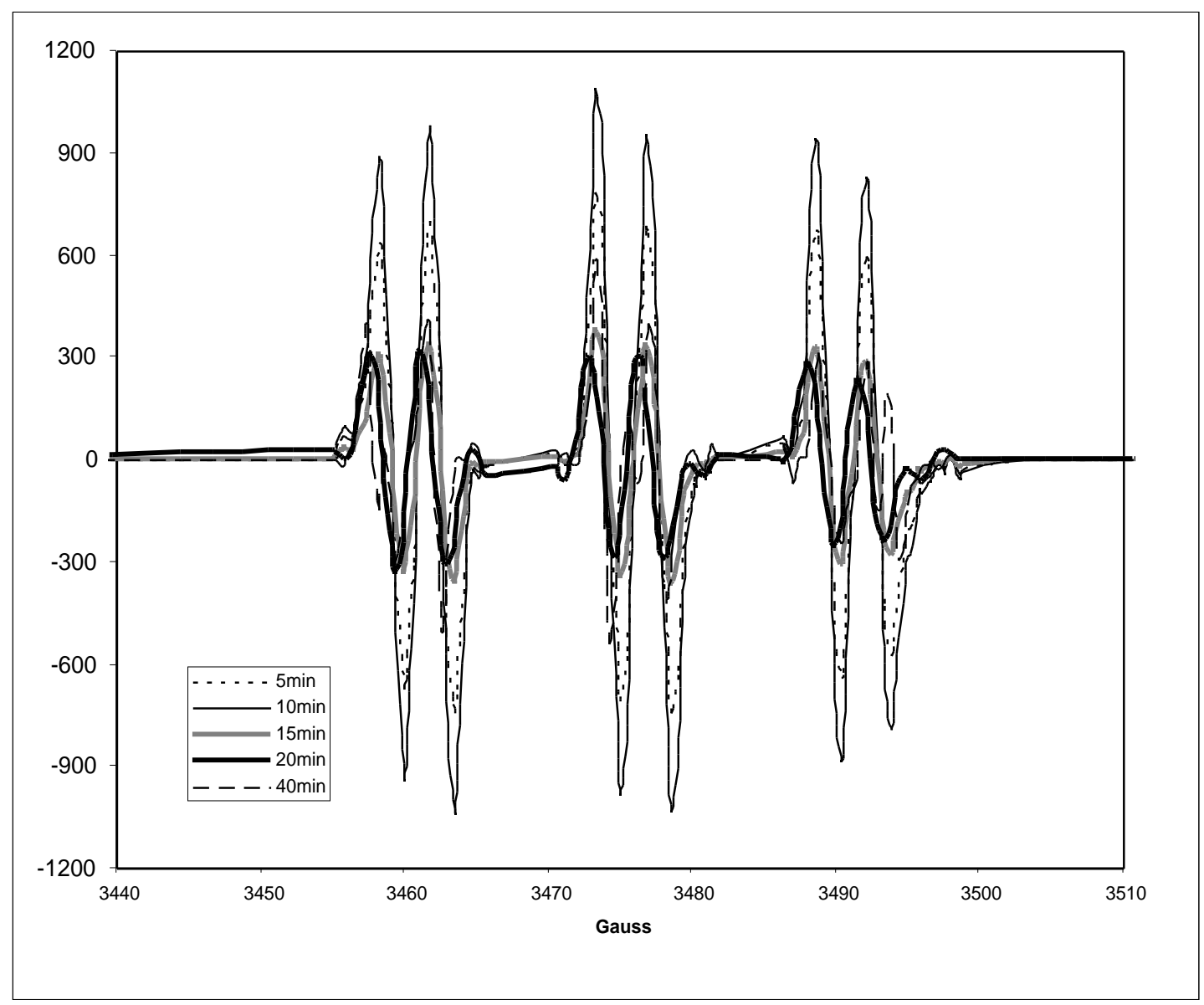

Fig. 2: First - derivative ESR spectrum indicating the accumulation of PBN-phenyl during sonication of 2-PCB $(4.6 \mu \mathrm{M})$ at $20 \mathrm{kHz}$ and $30.4 \mathrm{Wcm}^{-2}$ in an $\mathrm{Ar}$ saturated solution. A maximum peak area occurs after 10 minutes of sonication. 

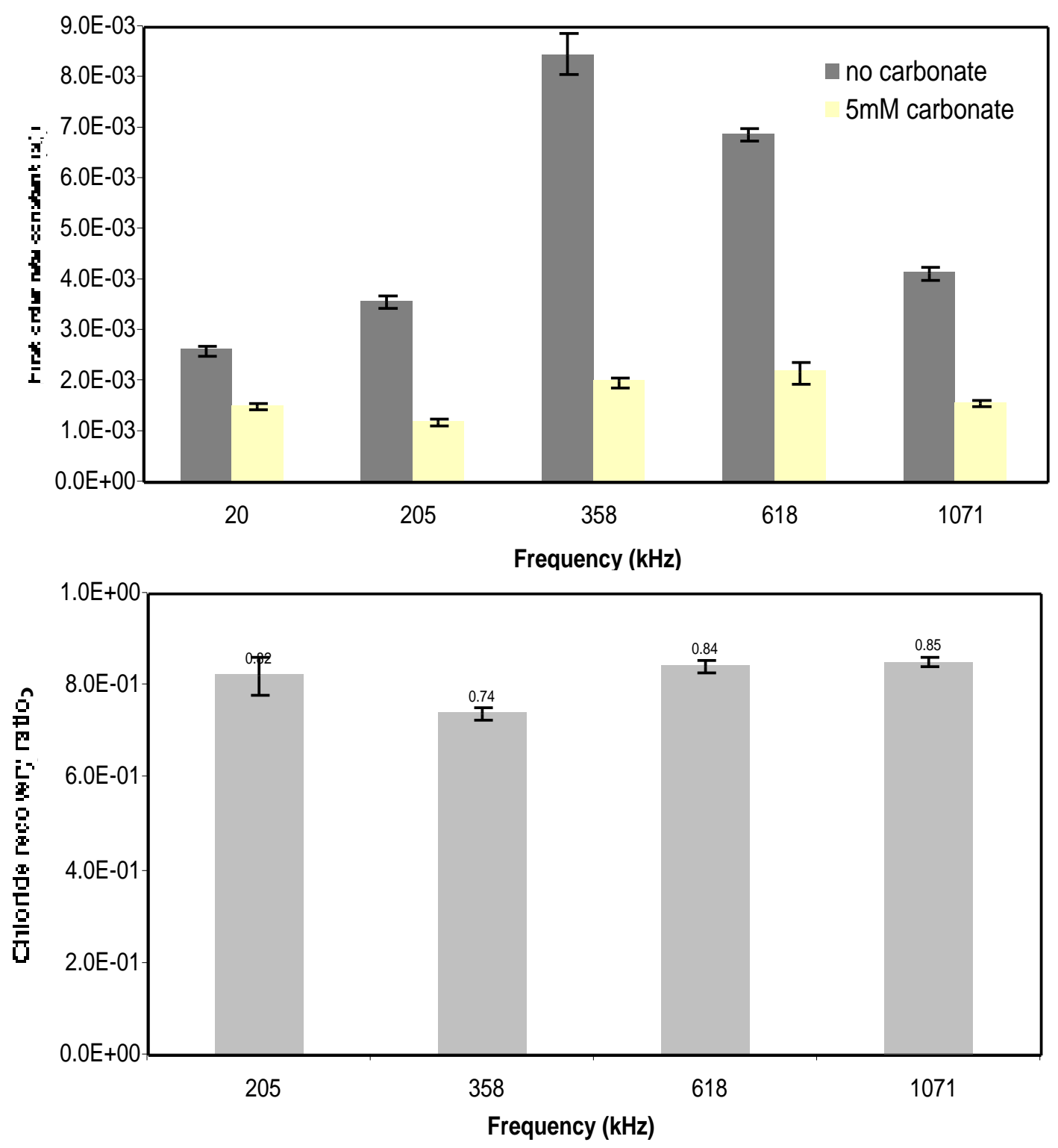

Fig. 3 (top): Observed rate constants for PCB destruction with and without carbonate.

Fig.4 (bottom): chloride recovery at different frequencies. 2-PCB (5.2_M) in an Ar-saturated solution, $\mathrm{I}=5.5 \mathrm{~W} \mathrm{~cm}^{-2}$. 


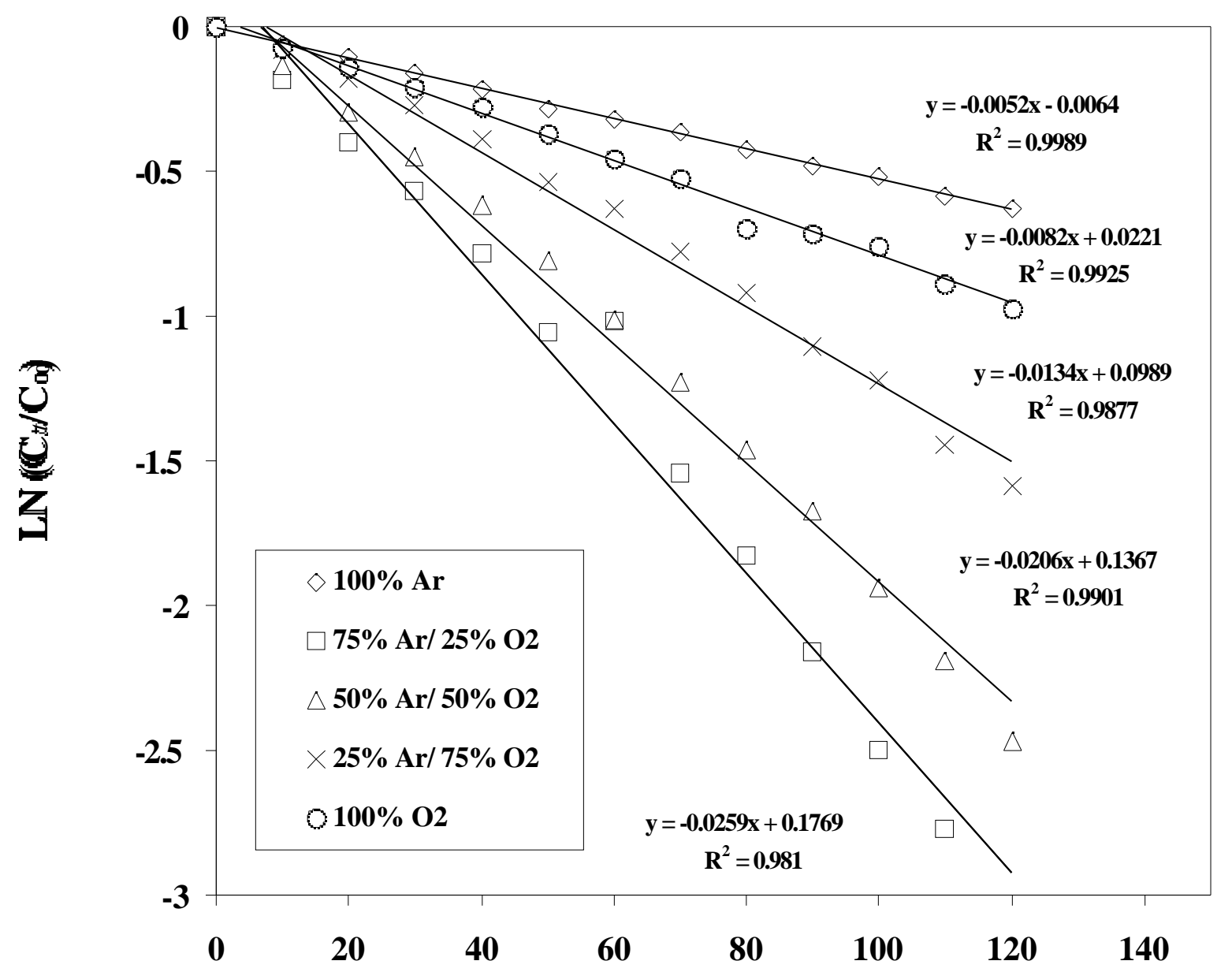

Time (minutes)

Figure 5. 1,4 - dioxane degradation with various gas sparge ratios. Reactor conditions: power intensity $=5.1 \mathrm{~W} / \mathrm{cm}^{2}$, frequency $=358 \mathrm{kHz}, \mathrm{C}_{\mathrm{o}}=1.0 \mathrm{mM}, \mathrm{C}_{t}=$ concentration at time $t$. Results are averaged from experiments performed in duplicate. 


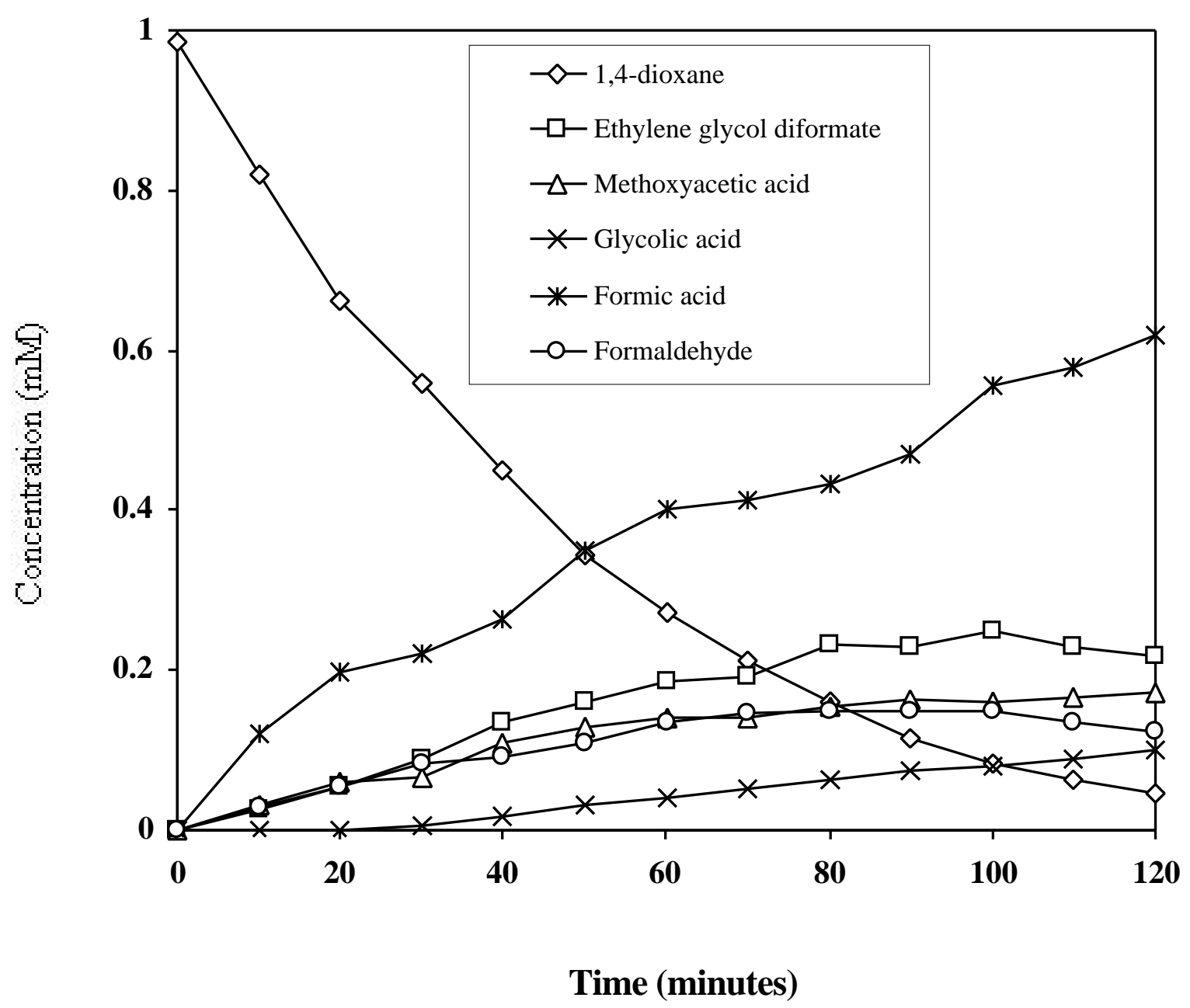

Figure 6. Formation of sonolytic by-products of 1,4-dioxane over time. Reactor conditions: frequency $=358 \mathrm{kHz}$, sparge gas ratio $=75 \% / 25 \%\left(\mathrm{Ar} / \mathrm{O}_{2}\right)$, power intensity $=5.1$ $\mathrm{W} / \mathrm{cm}^{2}, \mathrm{C}_{\mathrm{o}}=1.0 \mathrm{mM}$. Results are averaged from experiments performed in triplicate. 


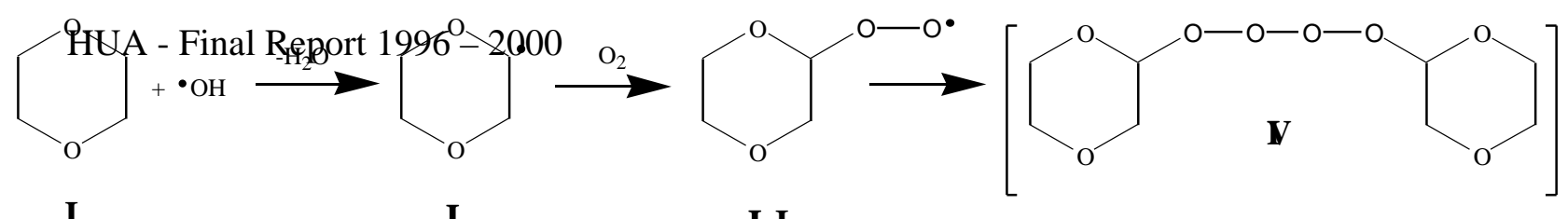

I

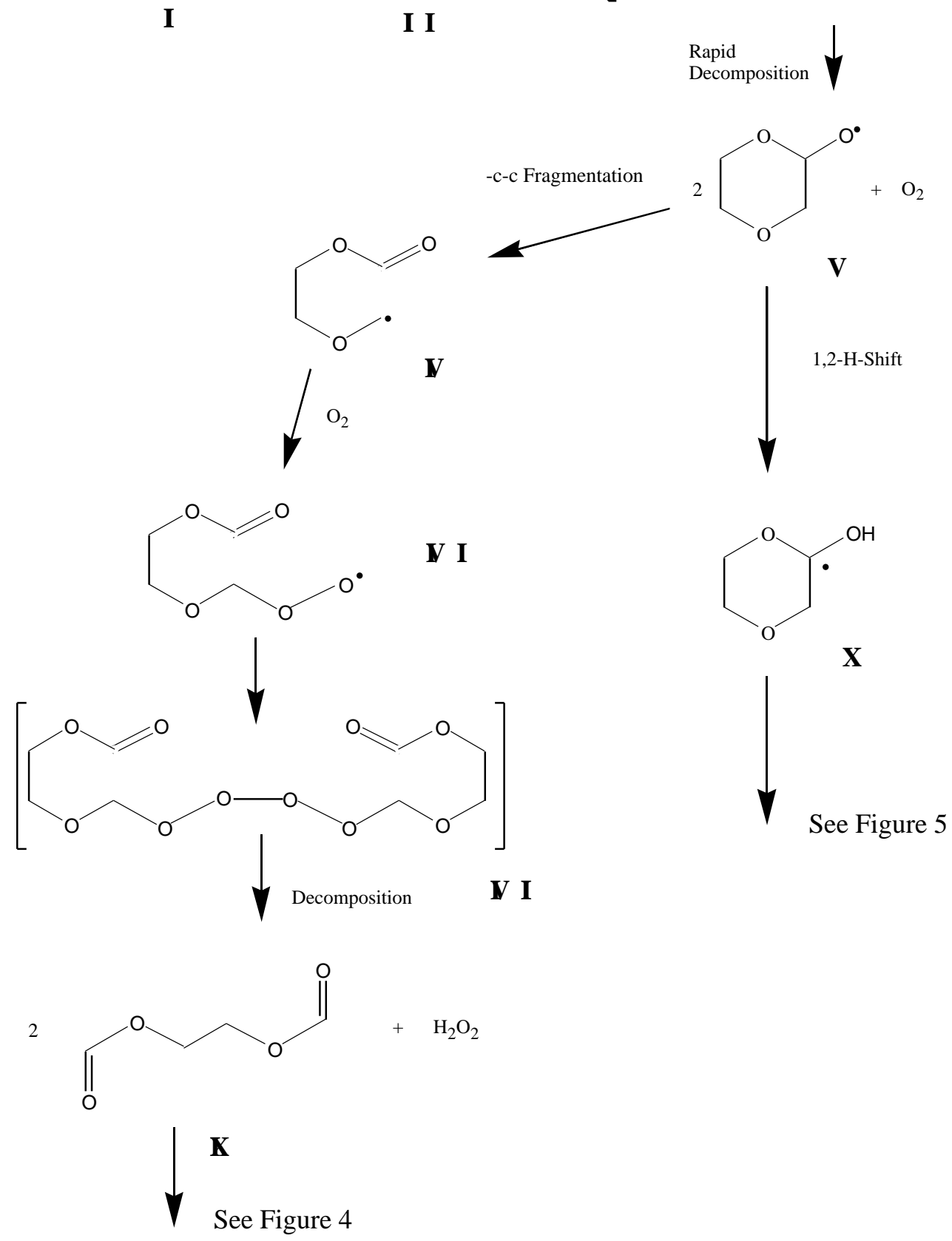

Figure 7. Reaction scheme of the initial degradation mechanism for 1,4-dioxane. Reactions took place under the following conditions: sparge gas ratio $=75 \% / 25 \%\left(\mathrm{Ar} / \mathrm{O}_{2}\right)$, power intensity $=5.1 \mathrm{~W} / \mathrm{cm}^{2}$, frequency $=358 \mathrm{kHz}, \mathrm{C}_{\mathrm{o}}=1.0 \mathrm{mM}$. The major intermediates observed in this study are highlighted in boxes. 


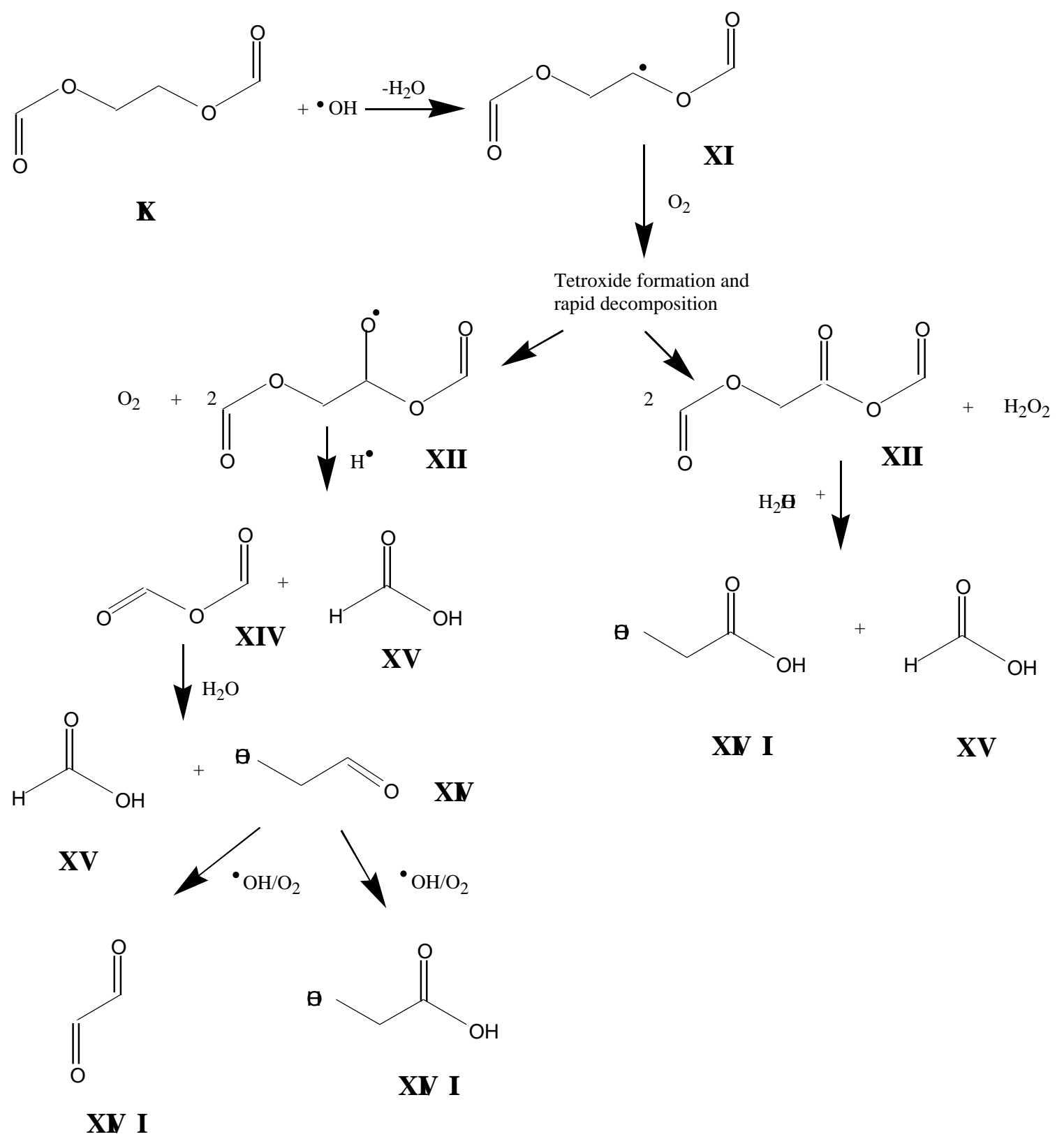

Figure 8. Reaction scheme for the sonolytic degradation of ethylene glycol diformate (EGD). Scheme continued from Figure 3. The tetroxide intermediate mentioned here is structurally different than the one shown in Figure 3. 


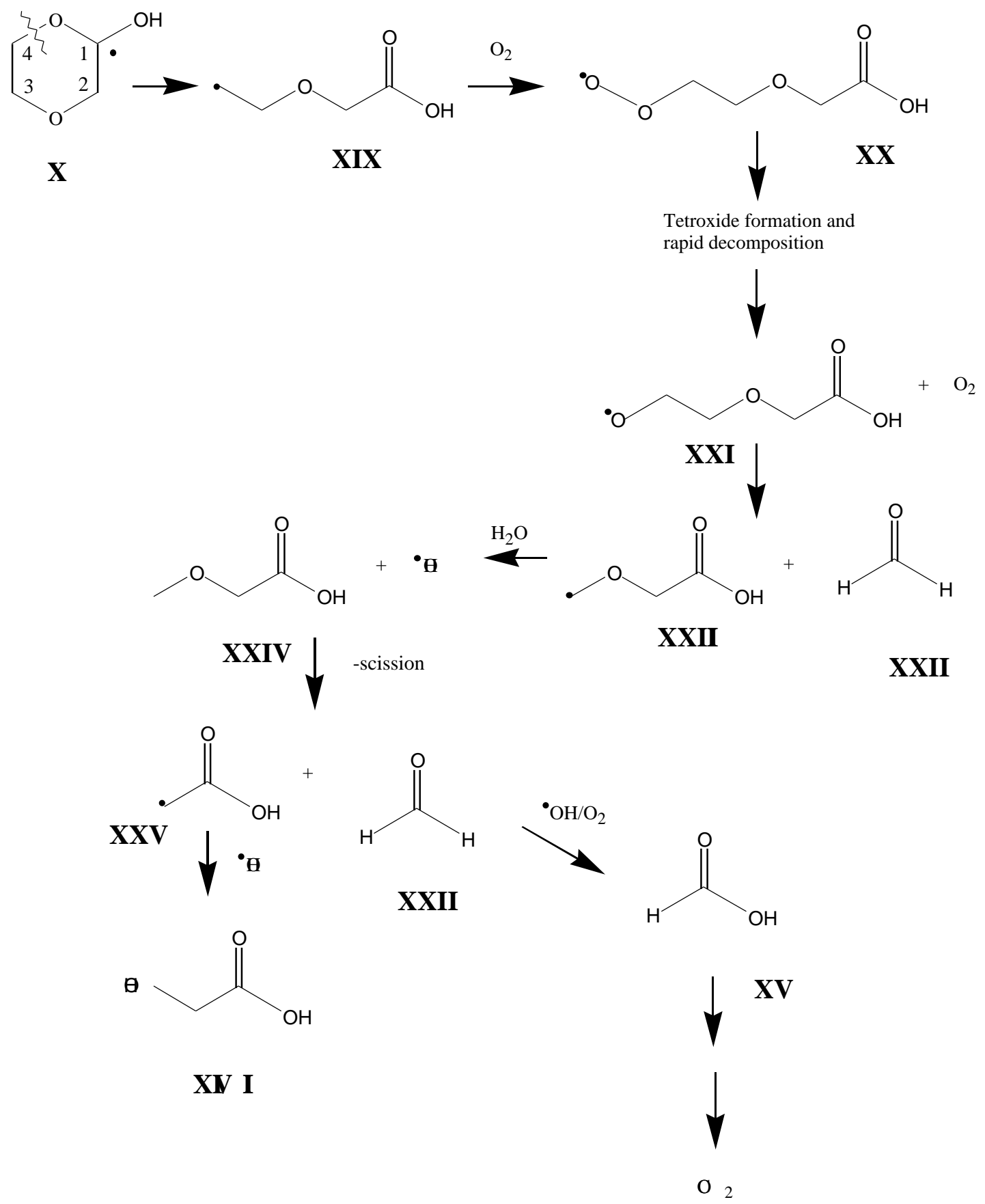

Figure 9. Reaction scheme for the pathway to methoxyacetic acid and decomposition. Scheme continued from Figure 3. 


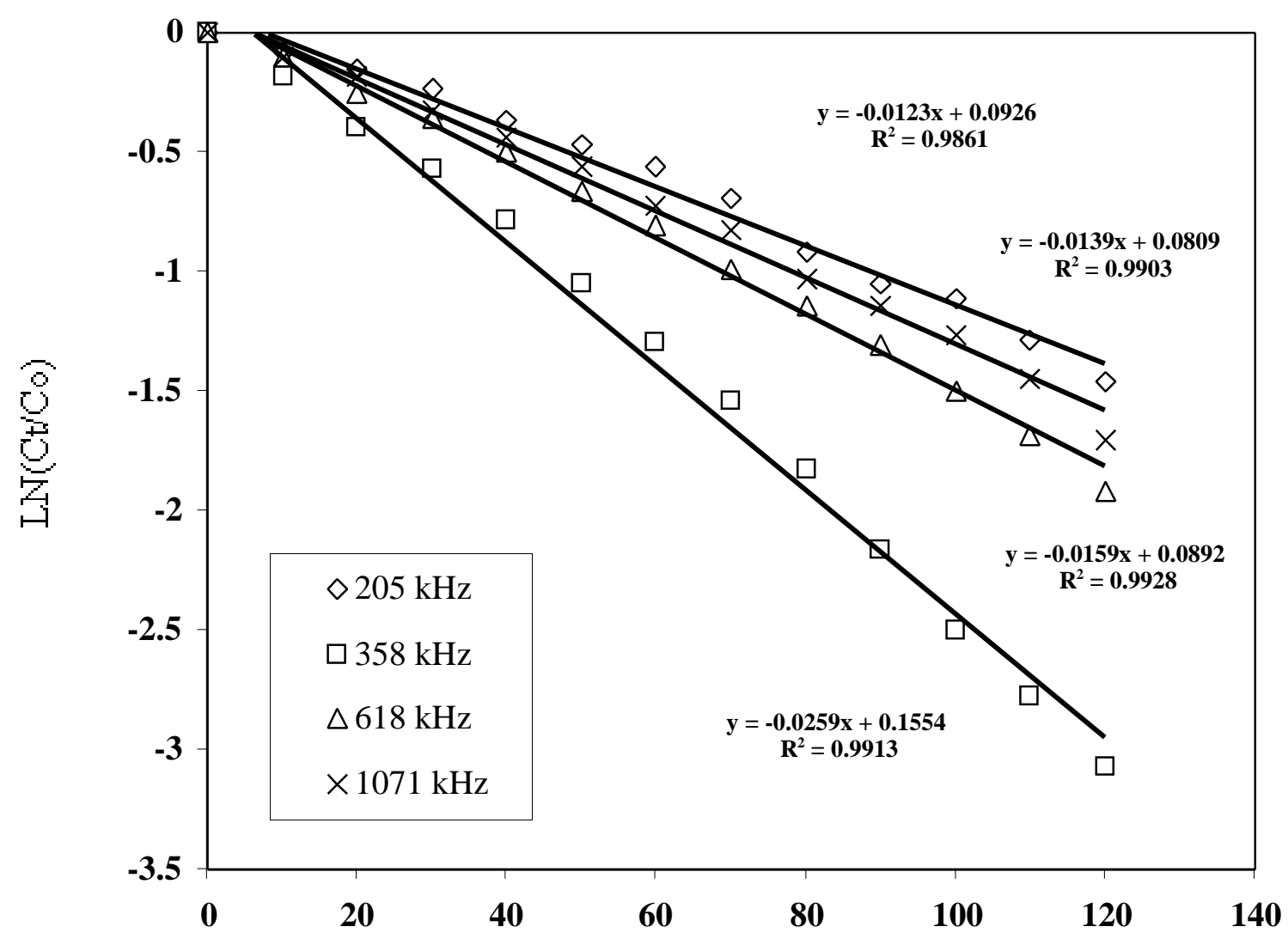

Time (minutes)

Figure 10. 1,4-dioxane degradation at four ultrasonic frequencies. Reactor conditions: Power intensity $=5.1 \mathrm{~W} / \mathrm{cm}^{2}$, sparge gas ratio $=75 \% \mathrm{Ar} / 25 \% \mathrm{O}_{2}, \mathrm{C}_{\mathrm{o}}=1.0 \mathrm{mM}, \mathrm{T}=25^{\circ} \mathrm{C}$. 
HU1A) Final Report $1996-2000$

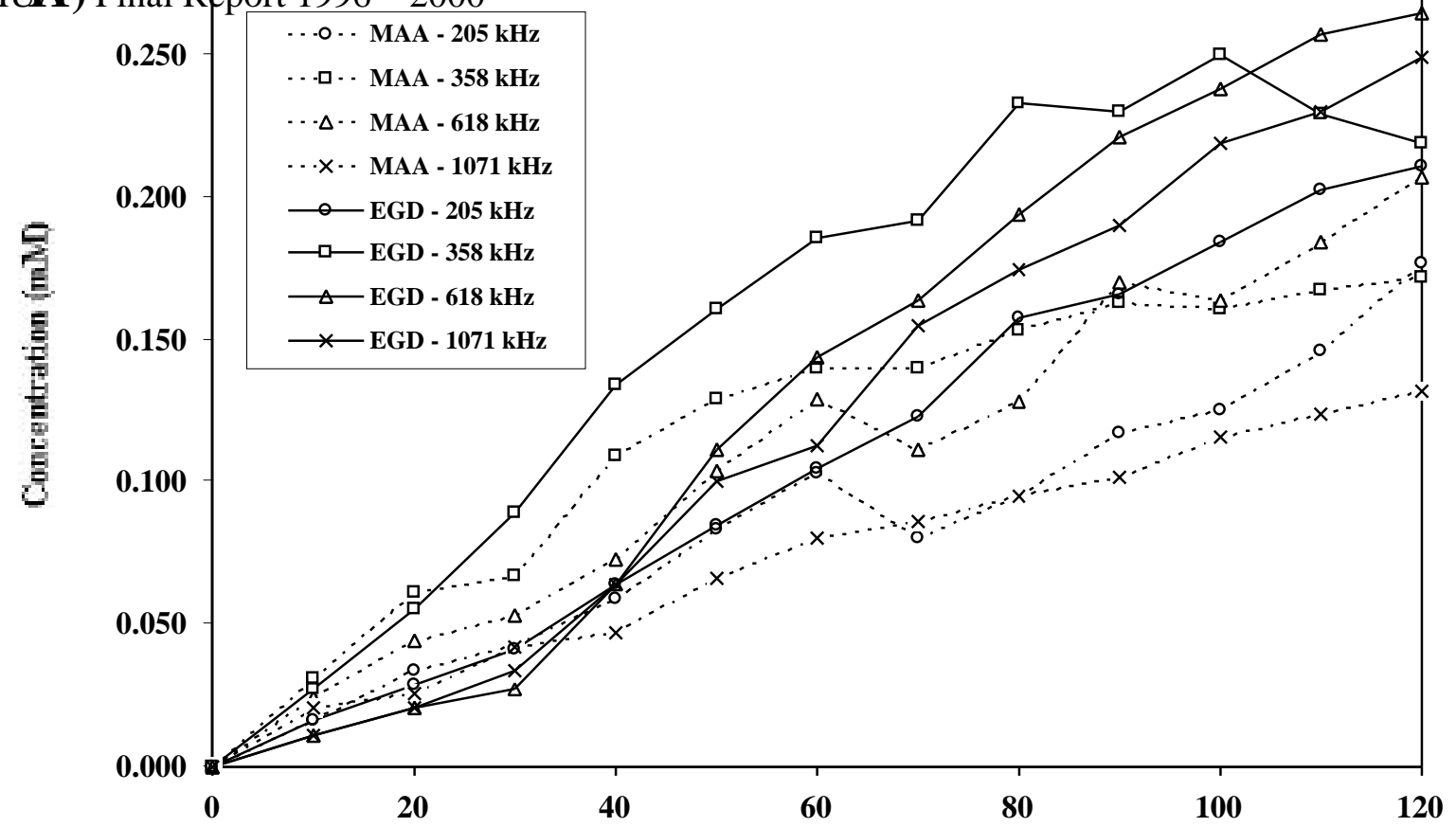

12)

0.700

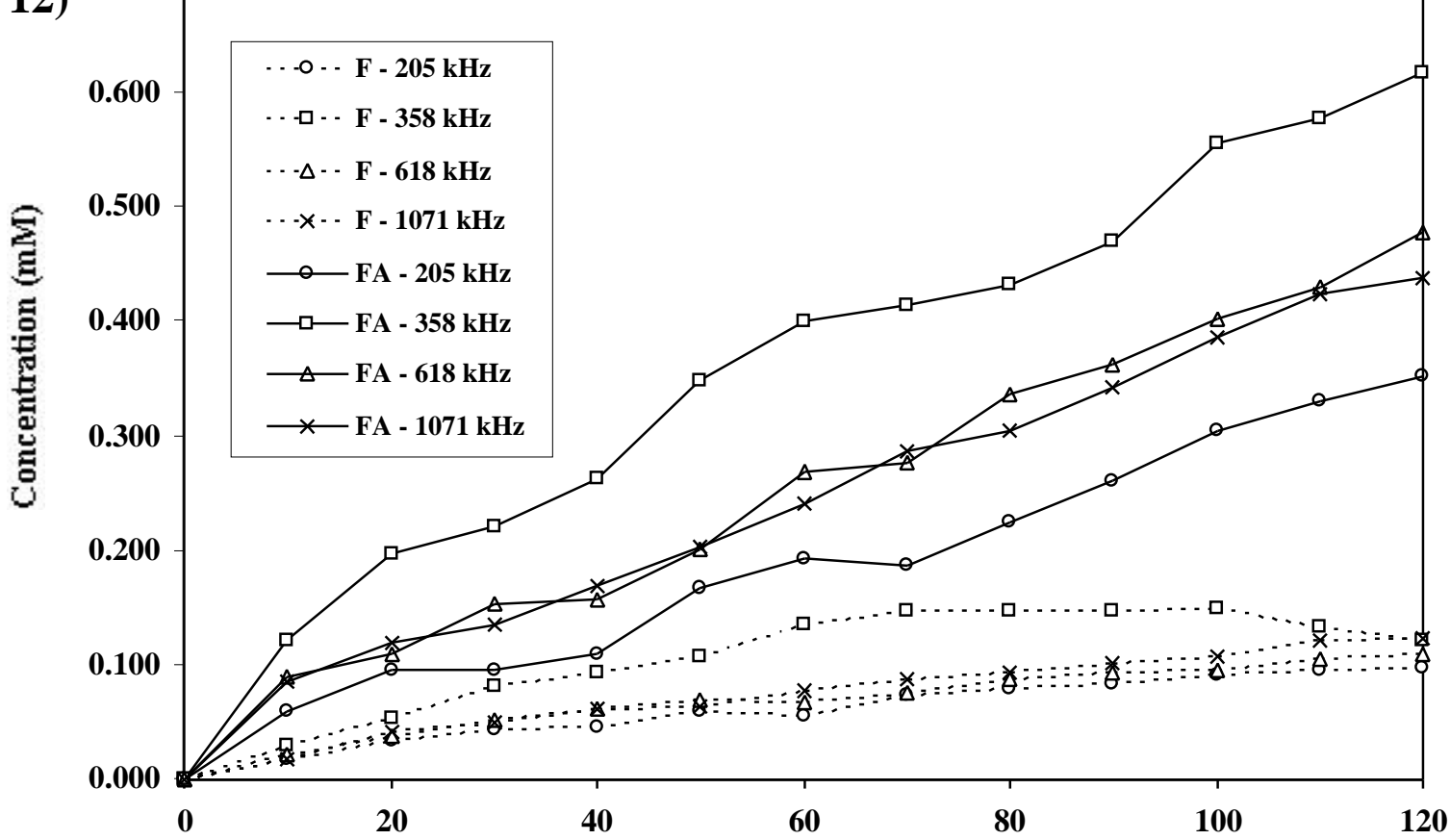

Time (minutes)

Figure 11: Formation of methoxyacetic acid (MAA) and ethylene glycol diformate (EGD)

Figure 12: Formation of formaldehyde (F) and formic acid (FA) over time. Conditions used: frequency $=205(\mathrm{O}), 358(\mathbf{O}), 618(\Delta), 1071(\mathrm{X}) \mathrm{kHz}$; sparge gas ratio $=75 \% / 25 \%\left(\mathrm{Ar} / \mathrm{O}_{2}\right)$, power intensity $=5.1 \mathrm{~W} / \mathrm{cm}^{2}, \mathrm{C}_{\mathrm{o}}=1.0 \mathrm{mM}$. . Results are averaged from experiments performed in triplicate. 
HUA - Final Report 1996 - 2000

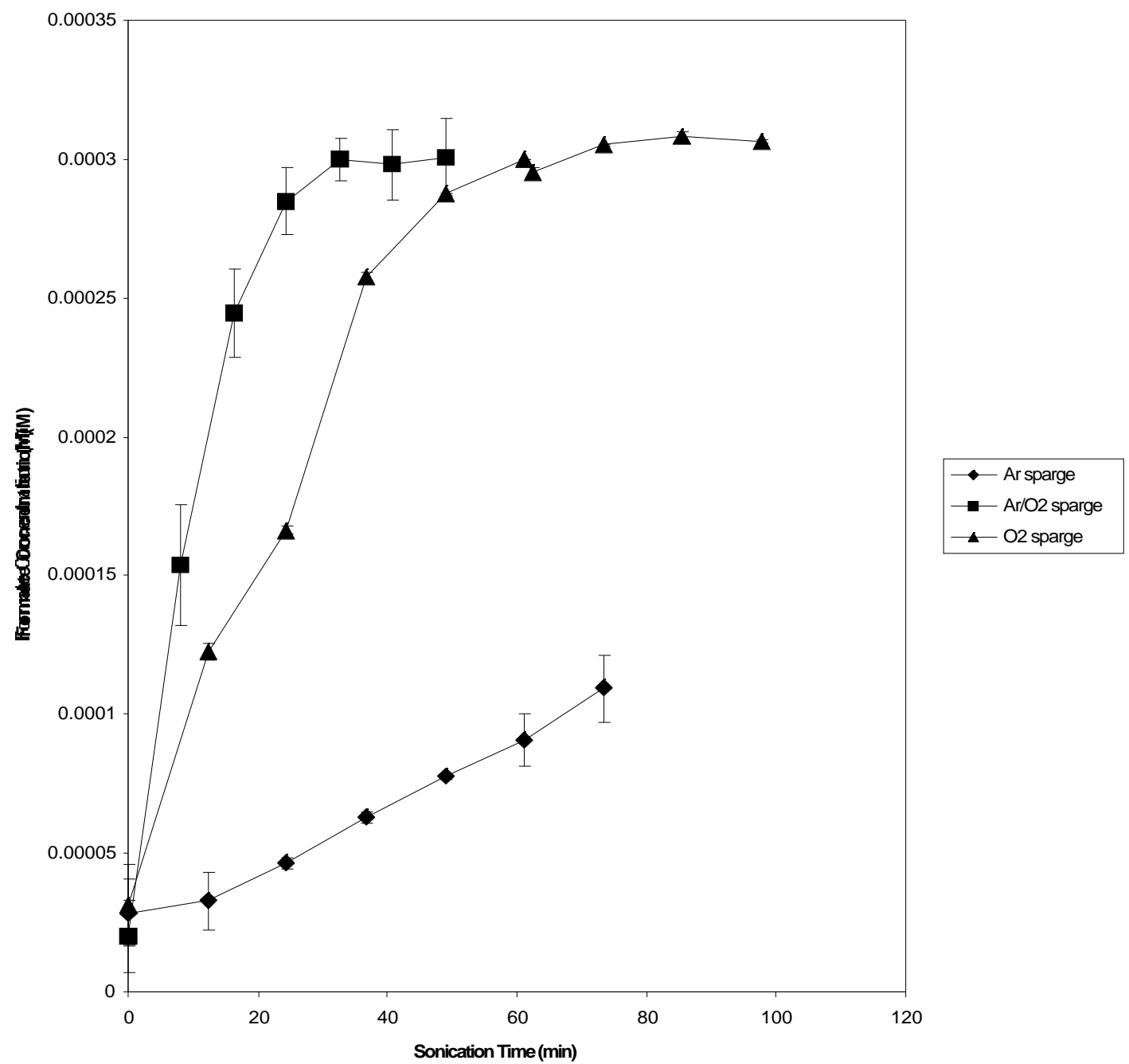

Figure 13. Impact of saturating gas on the accumulation of formate during sonication of dichlorvos at 161 Watts and $500 \mathrm{kHz}$. Initial dichlorvos concentration $=5.0 \times 10^{-4} \mathrm{M}$. 


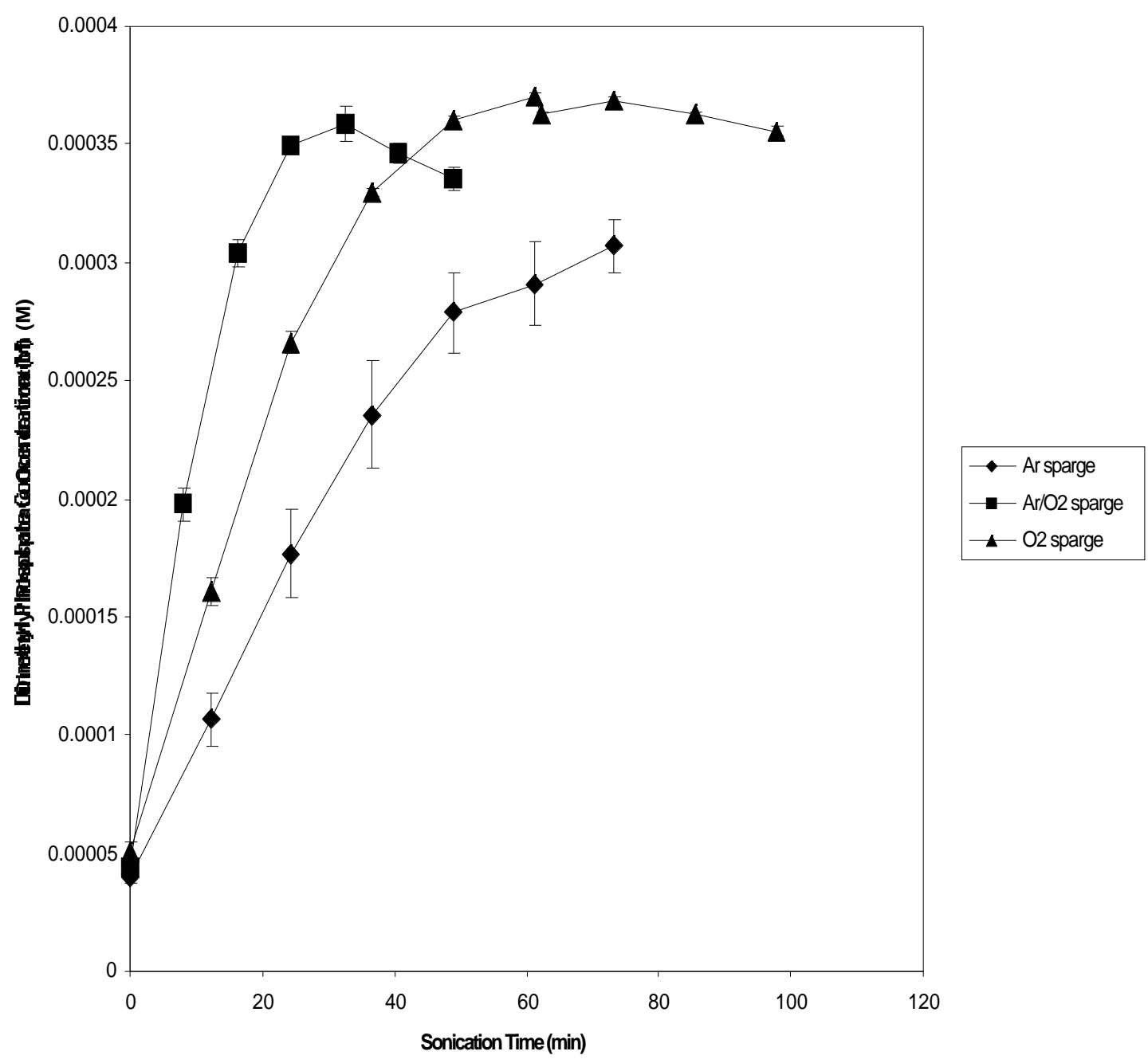

Figure 14. Impact of saturating gas on the accumulation of dimethyl phosphate during sonication of dichlorvos at 161 Watts and $500 \mathrm{kHz}$. Initial dichlorvos concentration $=5.0$ x $10^{-4} \mathrm{M}$, and sparge gas flow rate is $100 \mathrm{~mL}-\mathrm{min}^{-1}$. 
HUA - Final Report 1996 - 2000

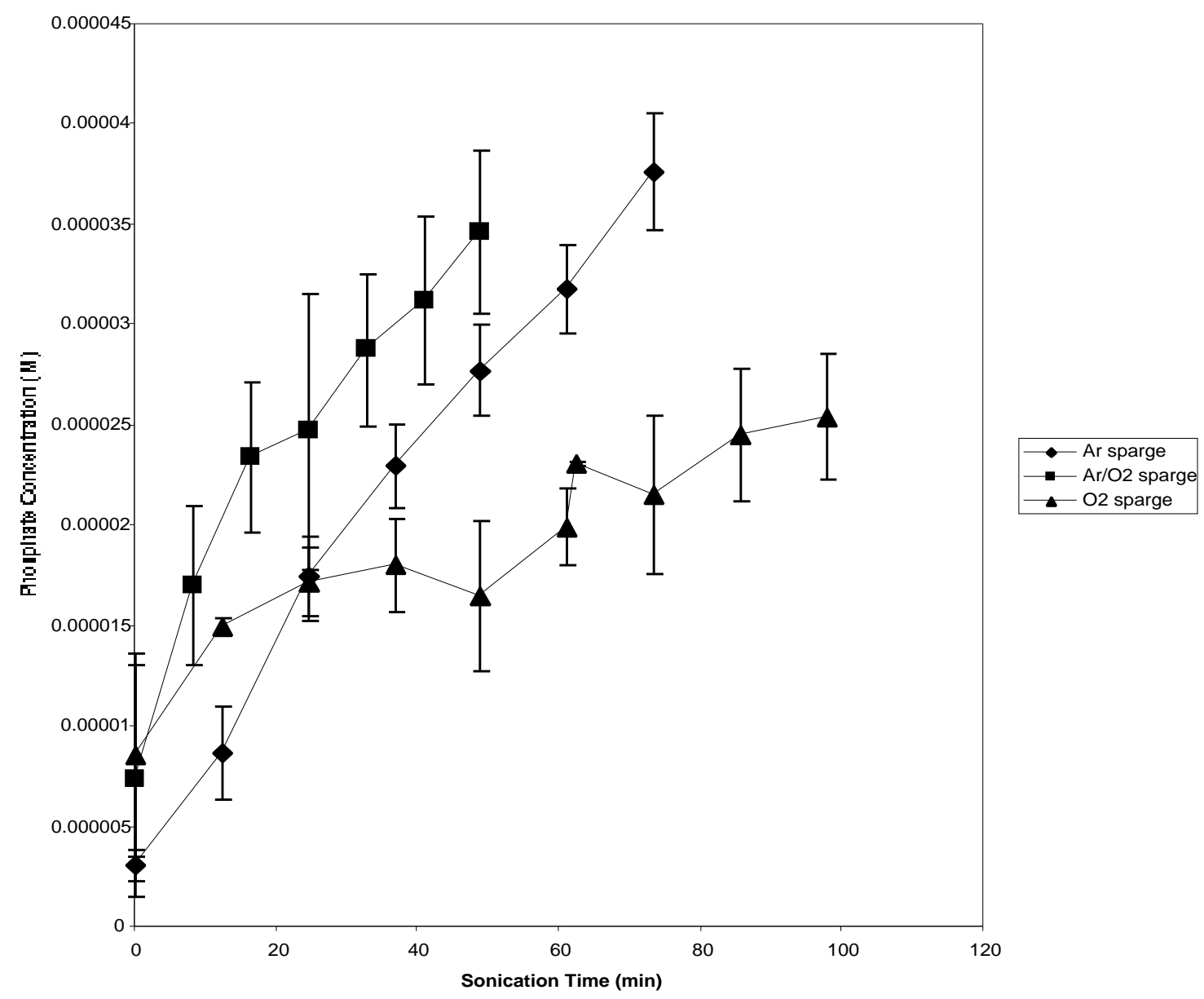

Figure 15. Impact of saturating gas on the accumulation of phosphate during sonication of dichlorvos at 161 Watts and $500 \mathrm{kHz}$. Initial dichlorvos concentration $=5.0 \times 10^{-4} \mathrm{M}$, and sparge gas flow rate is $100 \mathrm{~mL}-\mathrm{min}^{-1}$. 
HUA - Final Report 1996 - 2000

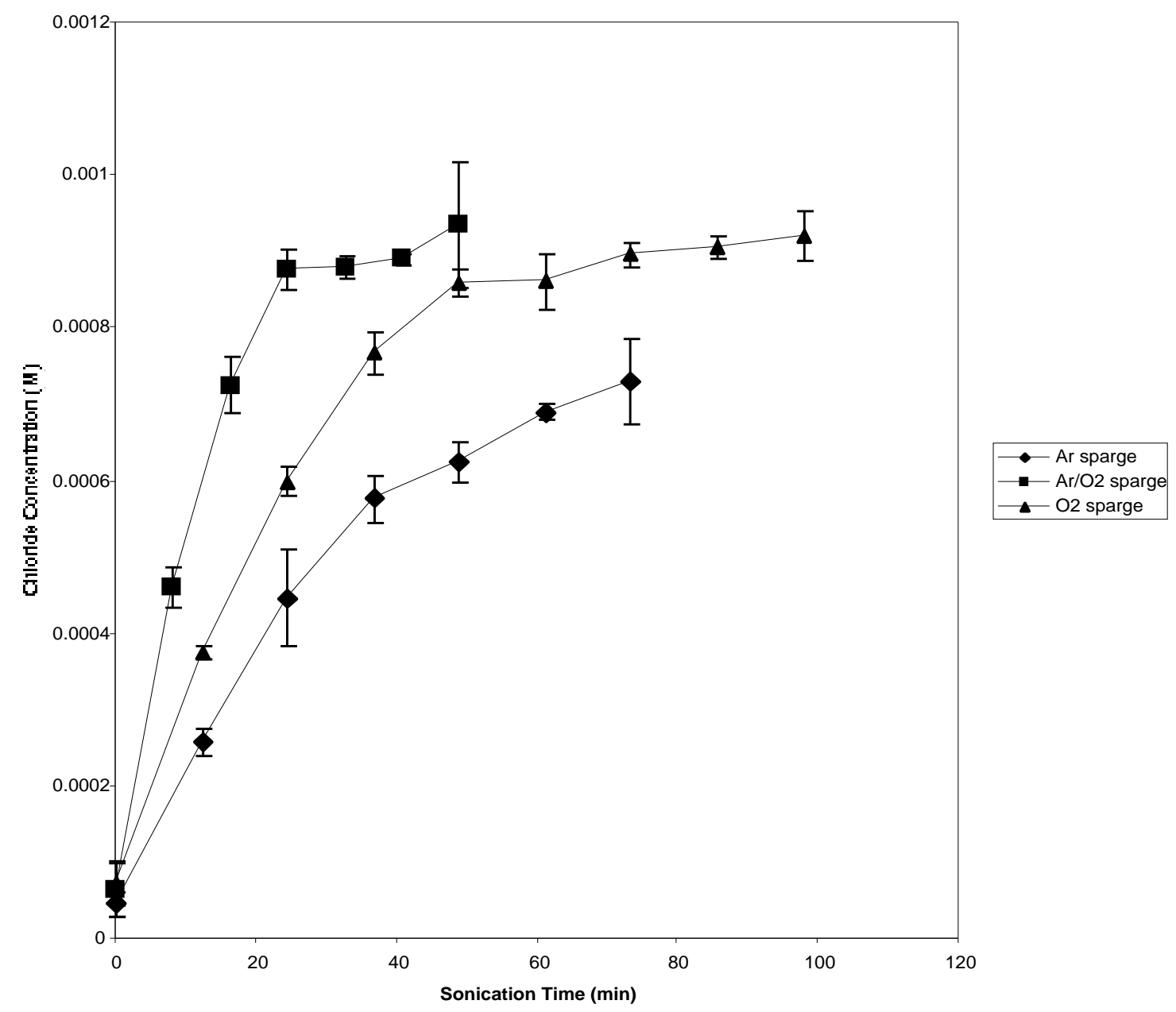

Figure 16. Impact of saturating gas on the accumulation of chloride ion during sonication of dichlorvos at $161 \mathrm{Watts}$ and $500 \mathrm{kHz}$. Initial dichlorvos concentration $=5.0 \times 10^{-4} \mathrm{M}$, and sparge gas flow rate is $100 \mathrm{~mL}-\mathrm{min}^{-1}$. 
HUA - Final Report 1996 - 2000

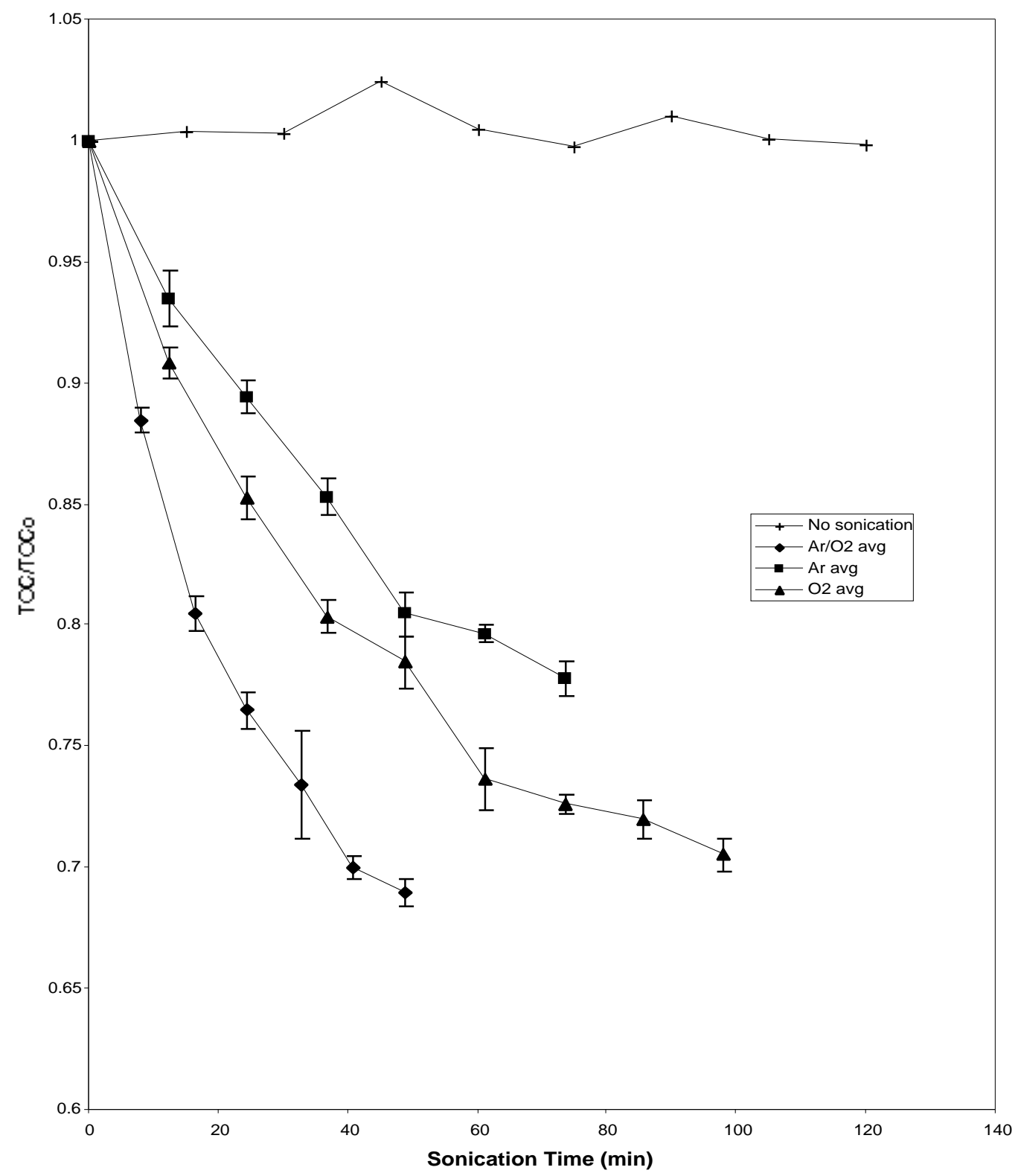

Figure 17. Conversion of organic carbon to $\mathrm{CO}_{2}$ during sonolysis of dichlorvos at $161 \mathrm{Watts}$ and $500 \mathrm{kHz}$. Initial dichlorvos concentration $=5.0 \times 10^{-4} \mathrm{M}$, and sparge gas flow rate is $100 \mathrm{~mL}-\mathrm{min}^{-}$ 1 . Note that the most rapid conversion occurs with a mixture of dissolved gases. 


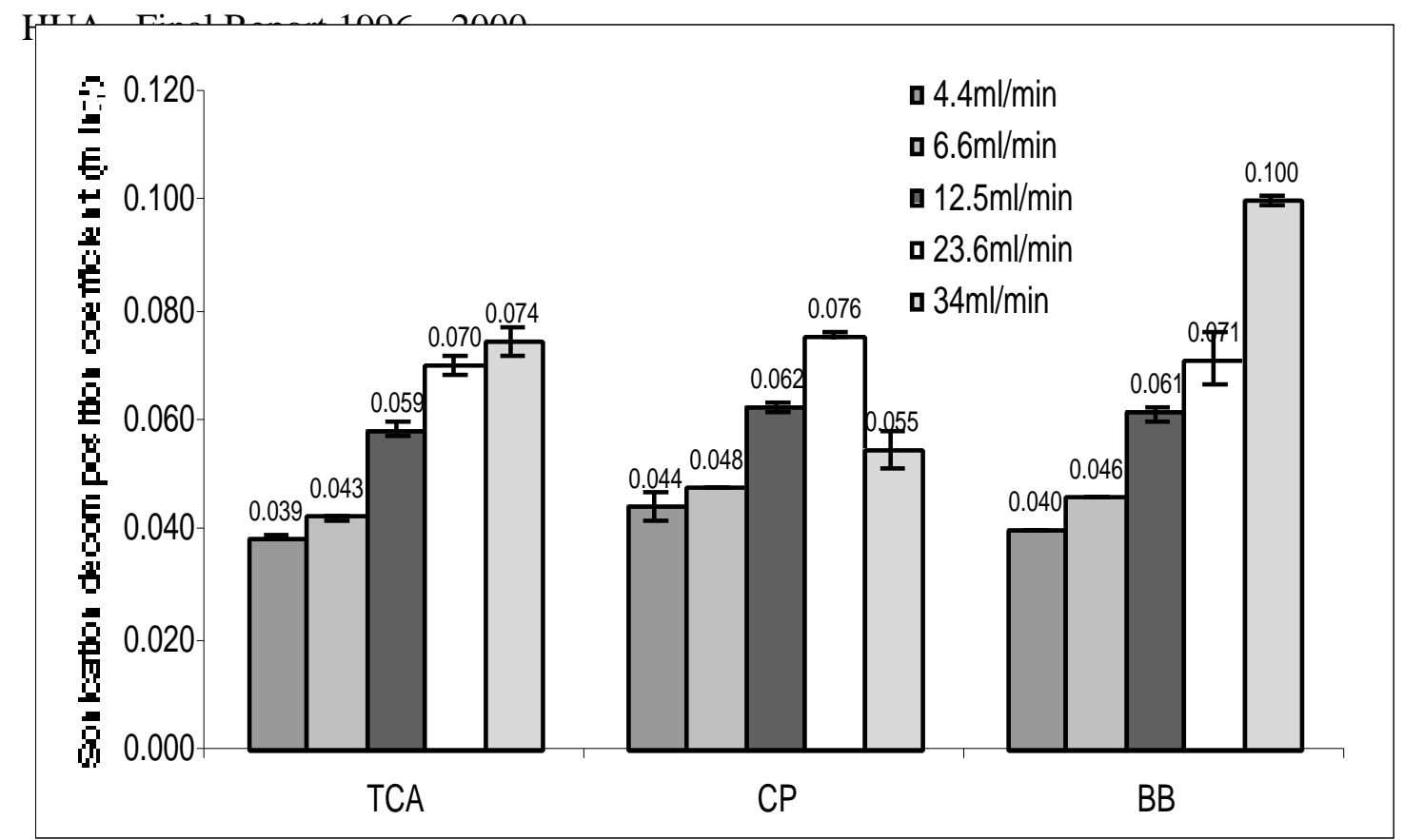

Figure 19: Impact of flow rate on decomposition coefficient in a continuous flow reactor operated at $20 \mathrm{kHz}$ and $30.8 \mathrm{~cm}^{-2}$, air-saturated solution. 


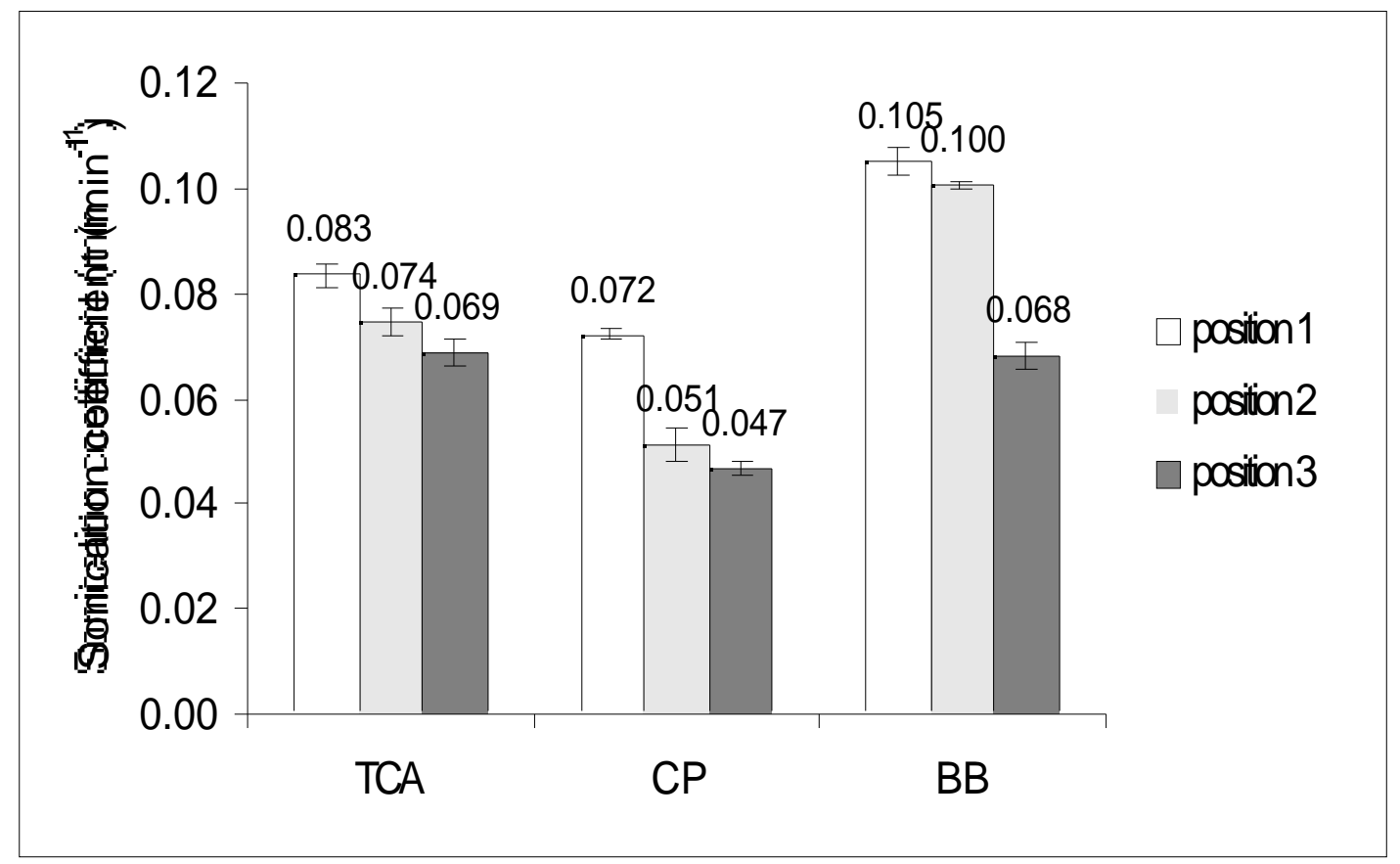

Figure 20: Impact of probe position on trichloroacetonitrile, chloropicrin, and bromobenzene decomposition. Operating conditions: $20 \mathrm{kHz}, 30.8 \mathrm{~W} \mathrm{~cm}$, and flow-rate $34 \mathrm{~mL} \mathrm{~min}^{-1}$. Positions 1, 2, and 3 correspond to probe placement 1.0, 7.6, and $14.2 \mathrm{~cm}$ downstream from the flow entrance into the reactor. 
HUA - Final Report 1996 - 2000

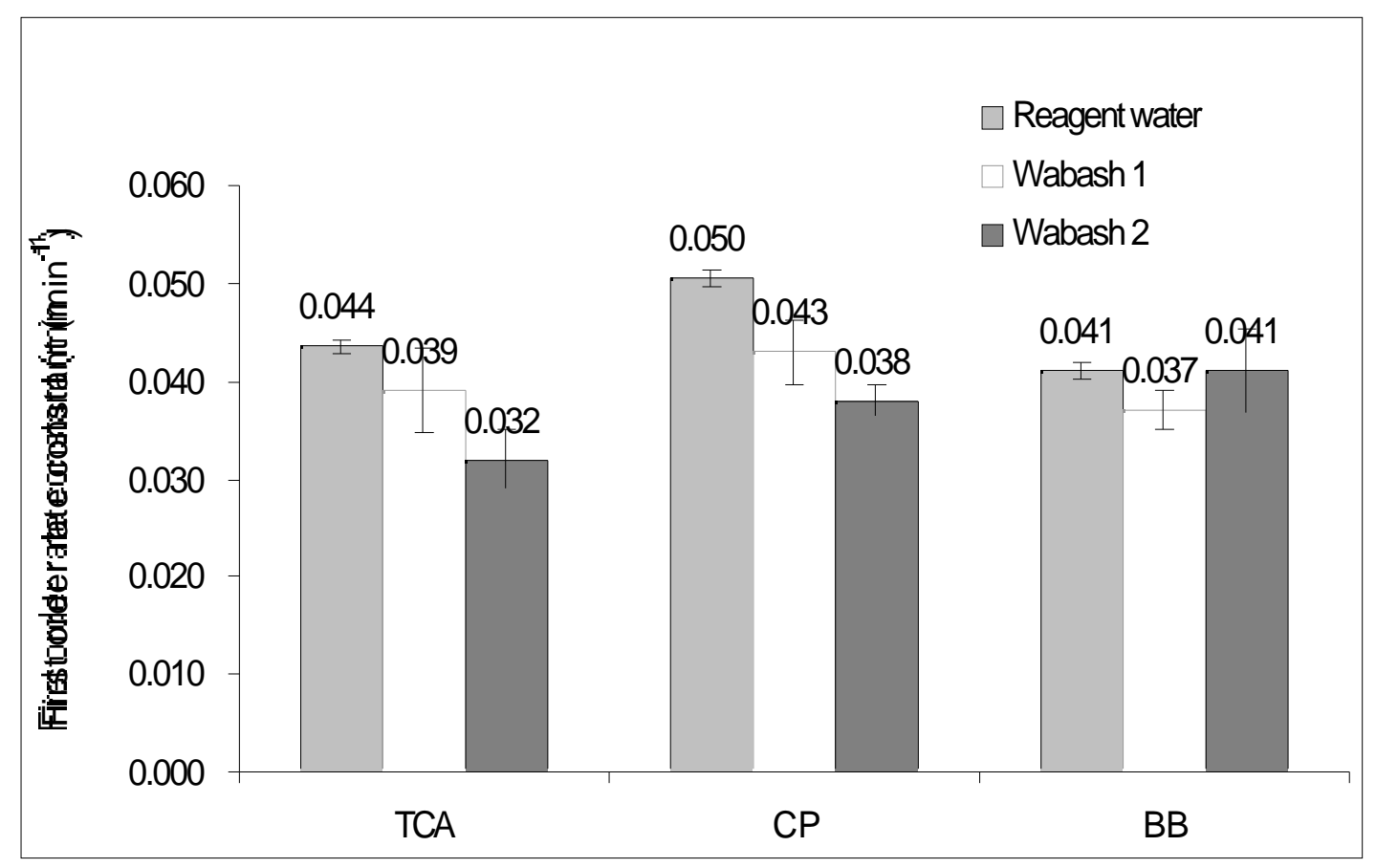

Figure 21: Sonication of trichloroacetonitrile, chloropicrin, and bromobenzene dissolved in Wabash River water. Experiments conducted in a batch reactor, at $20 \mathrm{kHz}$, and I $=30.8 \mathrm{Wcm}^{-2}$. 
HUA - Final Report 1996 - 2000

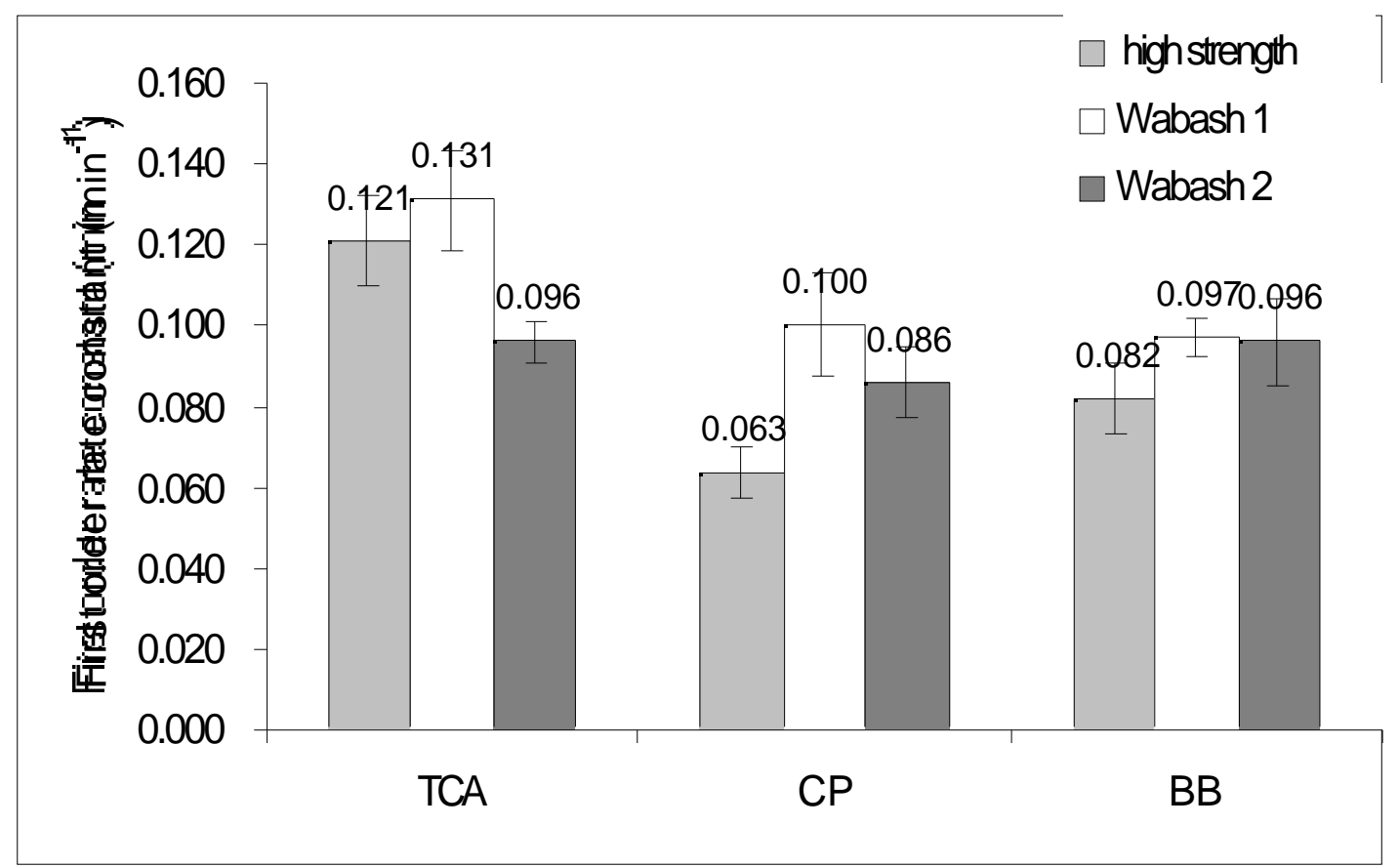

Figure 22: Sonication of trichloroacetonitrile, chloropicrin, and bromobenzene at $358 \mathrm{kHz}$ and $160 \mathrm{~W}$ in a batch reactor. 


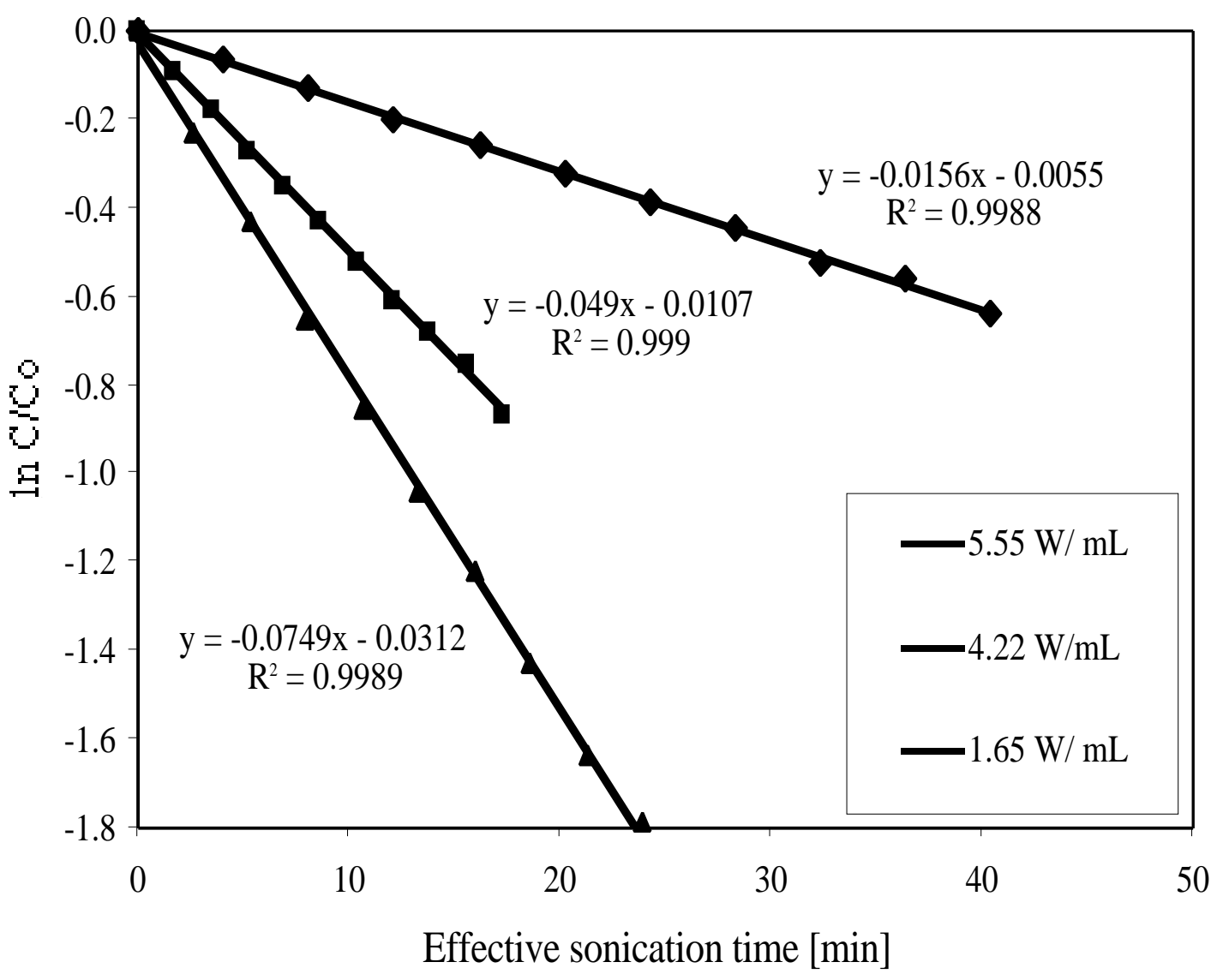

Figure 23: Pseudo-first order decomposition of carbofuran in the NAP reactor. Note that higher sound intensities correspond to faster decomposition.

\section{Publications Resulting from This Work}

1. Hua, * I., Höchemer, R.H., Hoffmann, M. R.; (1995) "Sonolytic Hydrolysis of $p$ Nitrophenlyacetate: The Role of Supercritical Water," Journal of Physical Chemistry, 99(8), pp. 2335-2342.

2. Hua, * I., Höchemer, R.H., Hoffmann, M. R.; (1995) “The Sonochemical Degradation of p-Nitrophenol in a Parallel-Plate Near-Field Acoustical Processor," Environmental Science and Technology, 29(11), pp. 2790-2796.

3. Hua,* I., Hoffmann, M. R.; (1996) "Kinetics and Mechanism of the Sonolytic Degradation of $\mathrm{CCl}_{4}$ : Intermediates and By-Products," Environmental Science and 
Technology, 30(3), pp. 864-871.

4. Hoffmann, M. R.; Hua, * I.; Höchemer, R.; (1996) “Application of Ultrasonic Irradiation for the Degradation of Chemical Contaminants in Water," Ultrasonics Sonochemistry, 3(3), pp. 163-172.

5. Weavers,* L. K., Hua, I., Hoffmann, M. R.; (1997) “A New Advanced Oxidation Process: Photoassisted Oxidation of Triethanolamine by Periodate," Water Environment Research, 69(6), pp. 1112-1119.

6. Hua, * I., Hoffmann, M. R; (1997) "Sonochemical Production of Hydroxyl Radical and Hydrogen Peroxide: The Effect of Frequency and Saturating Gas," Environmental Science and Technology, 31(8), pp. 2237-2243.

7. Zhang,* G. and Hua, I.; (2000) "Cavitation Chemistry of Polychlorinated Biphenyls: Decomposition Mechanisms and Rates," Environmental Science and Technology, 34(8), pp. 1529-1534.

8. Beckett,* M. A., and Hua, I.; (2000) "Elucidation of the 1,4-Dioxane Decomposition Pathway at Discrete Ultrasonic Frequencies," Environmental Science and Technology, 34 (19), pp. 3944-3953.

9. Zhang, * G., and Hua, I.; (2000) "Ultrasonic Degradation of Trichloroacetonitrile, Chloropicrin, Bromobenzene: Design Factors and Matrix Effects," Advances in Environmental Research, 4 (1), pp. 211-218.

10. Schramm,* J. and Hua, I.; (2000) "Ultrasonic Irradiation of Dichlorvos: Decomposition Mechanism and Mass Balances," 35(3), pp. 665-674, Water Research.

11. Hua,* I. and Thompson, J.; (2000) "Inactivation of Escherichia coli by Sonication at Discrete Ultrasonic Frequencies," Water Research, 34(15), pp. 3888-3893.

12. Hua,* I. and Pfalzer - Thompson, U.; (2000) "Ultrasonic Irradiation of Carbofuran: Decomposition Kinetics and Reactor Characterization," accepted for publication (August) in Water Research.

13. Beckett,* M. A. and Hua, I.; (2001) "The Impact of Ultrasonic Frequency on Aqueous Sonoluminescence and Sonochemistry," accepted for publication (February) in Journal of Physical Chemistry A.

14. Zhang, ${ }^{*}$ G. and Hua, I.; (2001) "The Impact of Particulates on Aqueous Sonochemical Reactions," accepted for publication (February), in Chemosphere.

\section{Acknowledgements:}

The authors wish to thank the United States Department of Energy (DOE Grant Number DE-FG07-96ER14710) for funding these studies. We also thank Dr. Carl Wood and Connie 
Bonham at the Mass Spectrometry Service Center of Purdue University for analysis of mass spectra, and Dr. Michael Everly of The Jonathan W. Amy Facility for Chemical Instrumentation (JAFCI) at Purdue University for help with the ESR experiments. Furthermore, the authors would like to thank Dr. Mihaela Stefan of the Siebens Drake Research Institute for helpful advice and Dr. Changhe Xiao of the School of Civil Engineering at Purdue University for analytical laboratory assistance. Finally, the authors would like to thank Wilmarie Flores and Rebecca Marquez for their efforts in performing some of the experiments. Jennifer Schramm was supported by the U. S. Department of Education (GAANN Fellowship) for part of this project. 